\title{
Choosing a suitable method for the identification of replication origins in microbial genomes
}

\author{
Chengcheng Song ${ }^{1,2,3}$, Shaocun Zhang ${ }^{1,2,3}$ and He Huang 1,2,3* \\ 'Department of Biochemical Engineering, School of Chemical Engineering and Technology, Tianjin University, Tianjin, China, \\ ${ }^{2}$ Key Laboratory of Systems Bioengineering, Ministry of Education, Tianjin University, Tianjin, China, ${ }^{3}$ Collaborative \\ Innovation Center of Chemical Science and Engineering, Tianjin, China
}

\section{OPEN ACCESS}

Edited by: Frank T. Robb,

University of Maryland, USA

Reviewed by:

Yoshizumi Ishino,

Kyushu University, Japan

Andrew F. Gardner,

New England Biolabs, USA

*Correspondence: He Huang,

Department of Biochemical Engineering, School of Chemical Engineering and Technology, Tianjin University, Tianjin 300072, China huang@tju.edu.cn

Specialty section: This article was submitted to Evolutionary and Genomic Microbiology,

a section of the journal Frontiers in Microbiology

Received: 03 April 2015 Accepted: 14 September 2015 Published: 30 September 2015

Citation:

Song $C$, Zhang $S$ and Huang $H$ (2015) Choosing a suitable method for the identification of replication origins in microbial genomes.

Front. Microbiol. 6:1049. doi: 10.3389/fmicb.2015.01049
As the replication of genomic DNA is arguably the most important task performed by a cell and given that it is controlled at the initiation stage, the events that occur at the replication origin play a central role in the cell cycle. Making sense of DNA replication origins is important for improving our capacity to study cellular processes and functions in the regulation of gene expression, genome integrity in much finer detail. Thus, clearly comprehending the positions and sequences of replication origins which are fundamental to chromosome organization and duplication is the first priority of all. In view of such important roles of replication origins, tremendous work has been aimed at identifying and testing the specificity of replication origins. A number of computational tools based on various skew types have been developed to predict replication origins. Using various in silico approaches such as Ori-Finder, and databases such as DoriC, researchers have predicted the locations of replication origins sites for thousands of bacterial chromosomes and archaeal genomes. Based on the predicted results, we should choose an effective method for identifying and confirming the interactions at origins of replication. Here we describe the main existing experimental methods that aimed to determine the replication origin regions and list some of the many the practical applications of these methods.

Keywords: replication origin, EMSA, Dnase I footprinting, SPR, RIP mapping, ITC, ChIP, ChIP-seq

\section{Introduction}

Genome duplication is essential for cellular life. Since the determination of complete genome sequences of many species, attention has been given to the understanding of DNA replication. There are important differences among bacteria, archaea, and eukaryotes in the process of DNA replication, but they all have the same core components of replication machines: DNA polymerases, circular sliding clamps, a pentameric clamp loader, helicase, primase, and single-strand binding protein (SSB) (Waga and Stillman, 1998; Garg and Burgers, 2005; Johnson and O'Donnell, 2005; Barry and Bell, 2006). The number of replication origins varies in terms of different evolutionary lineages (Aves, 2009). In bacteria, a single DNA replication origin is sufficient enough to ensure complete and opportune replication of the entire genome precisely once in each cell cycle. In the case of Escherichia coli, bacteria often contain only a single replication origin in one chromosome although not all bacteria follow this paradigm (Figure 1). Similarly, in archaea, single replication origins have been found in Pyrococcus and Archaeoglobus (Myllykallio et al., 2000; 


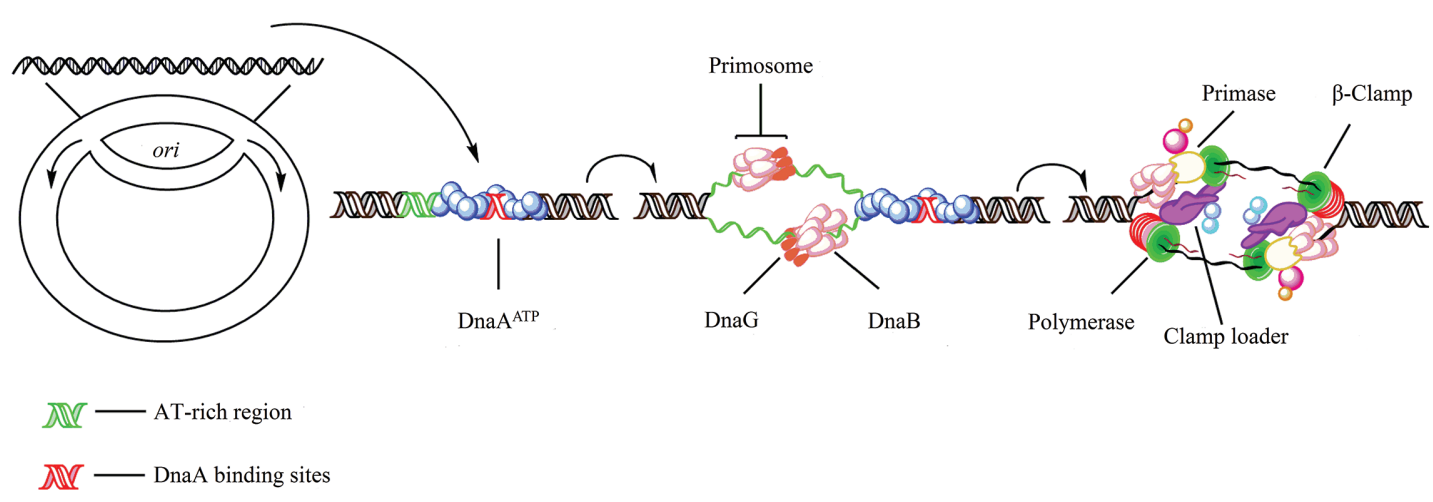

FIGURE 1 | Initiation of replication in bacteria. In Escherichia coli, replication initiation requires binding of the DNA-binding protein DnaA to DnaA-boxes at the chromosome origin oriC which is regulated by SeqA (Dame et al., 2011). Then, with the activation of ATP, two DnaB hexamers and the helicase loader DnaC, one double hexamer for each replication direction, are positioned by DnaA into the loop (Wahle et al., 1989; Skarstad and Katayama, 2013). Primase (DnaG) which can enter the complex and synthesize two leading strand primers, stimulates release of the regulatory protein DnaC from DnaB after transiently binding to the DnaB replicative helicase (Arias-Palomo et al., 2013). Also, DnaB binds to the sliding clamp loader, a ring-shaped dimer of the $\beta$-subunit which in turn binds the DNA polymerases III (Kelman and O’Donnell, 1995; O’Donnell et al., 2013).

Maisnier-Patin et al., 2002), two have been found in Aeropyrum (Robinson and Bell, 2007), three in Sulfolobales, four replication origins in the archaeon Pyrobaculum calidifontis (Pelve et al., 2012) and even multiple replication origins have been suggested in other genera, including Methanocaldococcus (Maisnier-Patin et al., 2002), Halobacterium (Berquist and DasSarma, 2003; Zhang and Zhang, 2003; Coker et al., 2009), and Haloferax (Norais et al., 2007). This illustrates how the events that occur at the DNA replication origins are predominant in the processes of DNA replication (Baker and Bell, 1998; Figure 2).

Initiator proteins were first proposed as the essential transacting factors for the initiation of DNA replication by Jacob et al. (1963). The initiator protein DnaA is the prerequisite protein in the process of prokaryotes DNA replication, and it plays an important role in forming an optimal initiation complex for DNA strand opening at the origin (Ozaki and Katayama, 2009). Among bacteria, the initiation of replication is best understood in E. coli. All functions of bacterial DnaA protein depend on its ability to bind specifically to an asymmetric 9-bp recognition sequence, the typical DnaA box: 5'-TTATNCACA$3^{\prime}$. The interactions DnaA binding to 9-mer DnaA boxes of the oriC is a high-affinity interaction ( $K D=1 \mathrm{nM}$ ) (Speck and Messer, 2001). The sequence of oriC usually consists of an array of several DnaA boxes and AT-rich regions. About 10-20 DnaA molecules form a homomultimeric initiation complex on the chromosomal replication origin, oriC. DnaA (52 kDa) consists of four functional domains, I, II, III, IV (Messer, 2002). The ssDNAbinding activity of DnaA domain I is weak (Abe et al., 2007), but

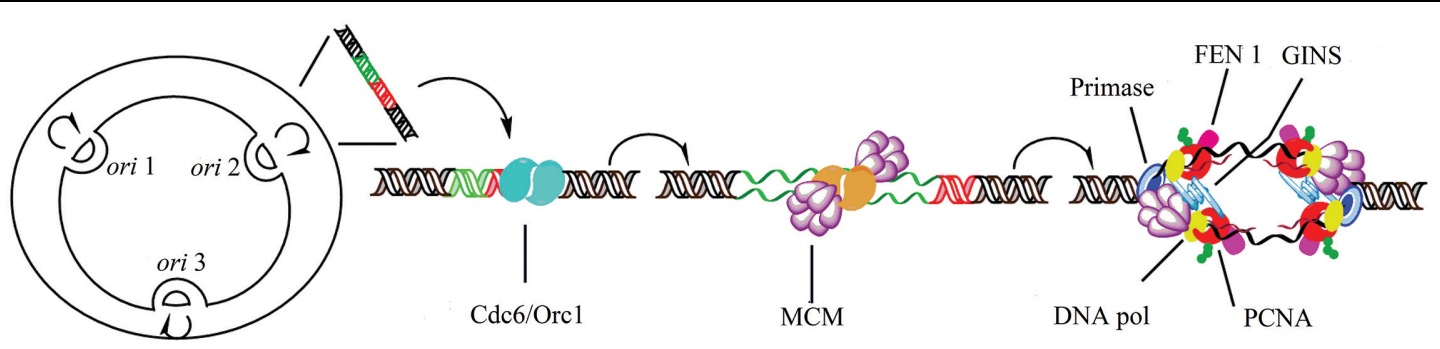

$$
\begin{aligned}
& \text { DIV — AT-rich region } \\
& \text { DUV - Cdc6/Orc1 binding sites }
\end{aligned}
$$

FIGURE 2 | Initiation of replication in archaea. Archaeal circular chromosome can contain a single or multiple origins (oriC). Archaea have the AAA+ Orc1/Cdc6 origin-binding protein, which shares extensive sequence homology with eukaryotic ORC proteins (Zhang et al., 2009). Minichromosome maintenance (MCM) proteins bind preferentially to the oriC region. ATP bound Cdc6/Orc1 associates with the Cdc6/Orc1-origin complex and with the MCM helicase. Following ATP hydrolysis the Cdc6/Orc1 protein releases the helicase, and the primase replaces the Cdc6/Orc1 protein binding to MCM. MCM interacts with the archaeal GINS (go, ichi, nii, san [five, one, two, three in Japanese]) complex (Marinsek et al., 2006) which is additionally capable of binding primase. Each DNA Pol interacts with a trimer of PCNA (proliferating cell nuclear antigen). The flap endonuclease FEN1 and DNA ligase I are only assembled to PCNA clamp of similar structure to E. coli $\beta$ (Michel and Bernander, 2014). 
the interactions between domain I and several proteins, including domain I itself, DnaB helicase, and the initiation stimulator DiaA, are required for DnaB helicase loading onto oriC open complexes flexible linker (Weigel et al., 1999; Felczak and Kaguni, 2004; Abe et al., 2007; Keyamura et al., 2007; Nozaki and Ogawa, 2008). Domain III plays a major role in ATP and ADP binding, in ATPdependent conformational changes of the DnaA multimer on oriC, in binding ssDNA of the oriC duplex unwinding element (DUE), and in ATP hydrolysis (Katayama, 2008; Ozaki et al., 2008). The C-terminal domain IV $(\sim 10 \mathrm{kDa})$ has a typical helixturn-helix fold that binds to DnaA box (Fujikawa et al., 2003). Domain IV Arg399 recognizes three more base pairs ( $5^{\prime}$ onethird of the DnaA box sequence: TTA) by base-specific hydrogen bonds in the minor groove of DNA (Fujikawa et al., 2003). Mostly, the C-terminal DnaA (IV) that was fused to a tag such as $\mathrm{His}_{6}$ or GST in the C-terminus or $\mathrm{N}$-terminus is necessary and sufficient for specific DNA binding (Richter and Messer, 1995; Roth and Messer, 1995; Sutton and Kaguni, 1997; Blaesing et al., 2000). DnaA binds to high- or low-affinity sites of origin and forms an oligomeric structure (Kawakami and Katayama, 2010) that involves two types of DnaA-DNA interactions, a doublestranded and a single-stranded DNA (Speck and Messer, 2001; Ozaki and Katayama, 2012). Furthermore, the DnaA protein is not only an initiator that binds to the specific site oriC but it is also a gene regulatory protein. There are about 300 high-affinity DnaA binding sites and a very large number of low-affinity sites around the chromosome (Kitagawa et al., 1996; Roth and Messer, 1998). Also, replication of microbial chromosome(s) occurs via the concerted action of many other origin binding proteins (oriBPs) which are cooperative with bacterial DnaA. The oriBPs includes factor for inversion stimulation (Fis), integration host factor (IHF), sequestration factor A (SeqA), aerobic respiration control (ArcA), inhibitor of chromosomal initiation (lciA) and that which binds specifically site(s) to oriC (Wolański et al., 2014). As reports have shown, only tens of origin regions of eubacteria and archaea have been confirmed experimentally (Myllykallio et al., 2000; Maisnier-Patin et al., 2002; Berquist and DasSarma, 2003; Matsunaga et al., 2003; Lundgren et al., 2004; Robinson et al., 2004; Norais et al., 2007; Coker et al., 2009).

A number of computational tools based on various skew types have been developed for predicting replication origins. Chromosome replication origins were mapped in vivo in the two hyperthermophilic archaea of Sulfolobus acidocaldarius (Duggin et al., 2008) and Sulfolobus solfataricus (Lundgren et al., 2004; Robinson et al., 2004), as well as in Haloarcula hispanica (Wu et al., 2013), haloarchaeon Halobacterium sp. NRC-1 model (Coker et al., 2009), Pyrobaculum calidifontis (Pelve et al., 2012), Nitrosopumilus maritimus (Pelve et al., 2013), and Haloferax mediterranei (Pelve et al., 2013), using high-throughput sequencing-based marker frequency (MF) analysis. MF analysis has been successfully used in combination with microarrays to study replication characteristics and to map chromosome replication origins in both bacteria (Khodursky et al., 2000) and eukaryotes (Raghuraman et al., 2001). Recently, the Web-based system Ori-Finder ${ }^{1}$ and

$\overline{{ }^{1} \text { http://tubic.tju.edu.cn/Ori-Finder/ }}$
Ori-Finder $2^{2}$ which utilize the Z-curve method and comparative genomics analysis were used to find oriCs in bacterial and archaeal genomes, respectively with high accuracy (Zhang and Zhang, 2005; Gao and Zhang, 2008; Gao, 2014; Luo et al., 2014). Ori-Finder 2 is also able to analyze the unannotated genome sequences by integrating them with gene prediction pipelines and BLAST software for gene identification and function annotation. The predicted oriC regions from Ori-Finder have been organized into an online database $\mathrm{DoriC}^{3}$, which contains oriCs for $>2000$ bacterial genomes and 100 archaeal genomes, respectively (Gao and Zhang, 2007; Gao et al., 2012, 2013). Based on the predicted results, we can identify and confirm the oriC by its interaction with the initiator protein DnaA, and by its ability to form higher-order structures with DnaA that can be seen in the electron microscope.

Over the past several years, the rapid development of techniques used for confirming protein-DNA interaction in vivo and in vitro, such as gel retardation assay, surface plasmon resonance (SPR), electrophoretic mobility shift assays (EMSA), the DNase I footprinting technique, replication initiation point (RIP) mapping, isothermal titration calorimetry (ITC), chromatin immunoprecipitation (ChIP), and ChIP sequencing (ChIP-seq) have resulted in an increasingly refined picture of the biochemical rules governing protein-DNA interactions. Protein-DNA interactions can be explored by various in vitro and in vivo strategies, which present different advantages and disadvantages. This review begins with a discussion of the main existing experimental methods that are applied to verify proteinDNA interactions in vivo and in vitro, as well as explore some functional components of the complexes, especially applied in detecting transcription factor binding sites. Then, we outline the main advantages and limitations of these methods in Table 1. Through the listed methods, we could choose the most suitable experimental strategy for identifying replication origins.

\section{Conventional Methods for Detecting Protein-DNA Interaction at Origins of Replication In Vitro}

\section{Electrophoretic Mobility Shift Assay}

The EMSA, also known as the band shift, gel shift, or gel retardation assay (Lane et al., 1992), is one of the most sensitive and straightforward methods to determine the binding site-size of the DNA binding protein using a series of DNA polymers even when the protein is at a low concentration within the extract (Carey et al., 2012). It is based on the principle that DNA/RNAprotein complexes migrate more slowly when subjected to non-denaturing polyacrylamide or agarose gel electrophoresis as compared to unbound free probe (Figure 3). The DNA probes used may be radiolabeled or dyes specific to stain DNA and protein may be used to visualize the DNA/RNA-protein interaction. In general poly $(\mathrm{dI}-\mathrm{dC})$ is added to abolish any nonspecific binding. Polyacrylamide gels offer better electrophoretic

${ }^{2}$ http://tubic.tju.edu.cn/Ori-Finder2/

${ }^{3}$ http://tubic.tju.edu.cn/doric/ 

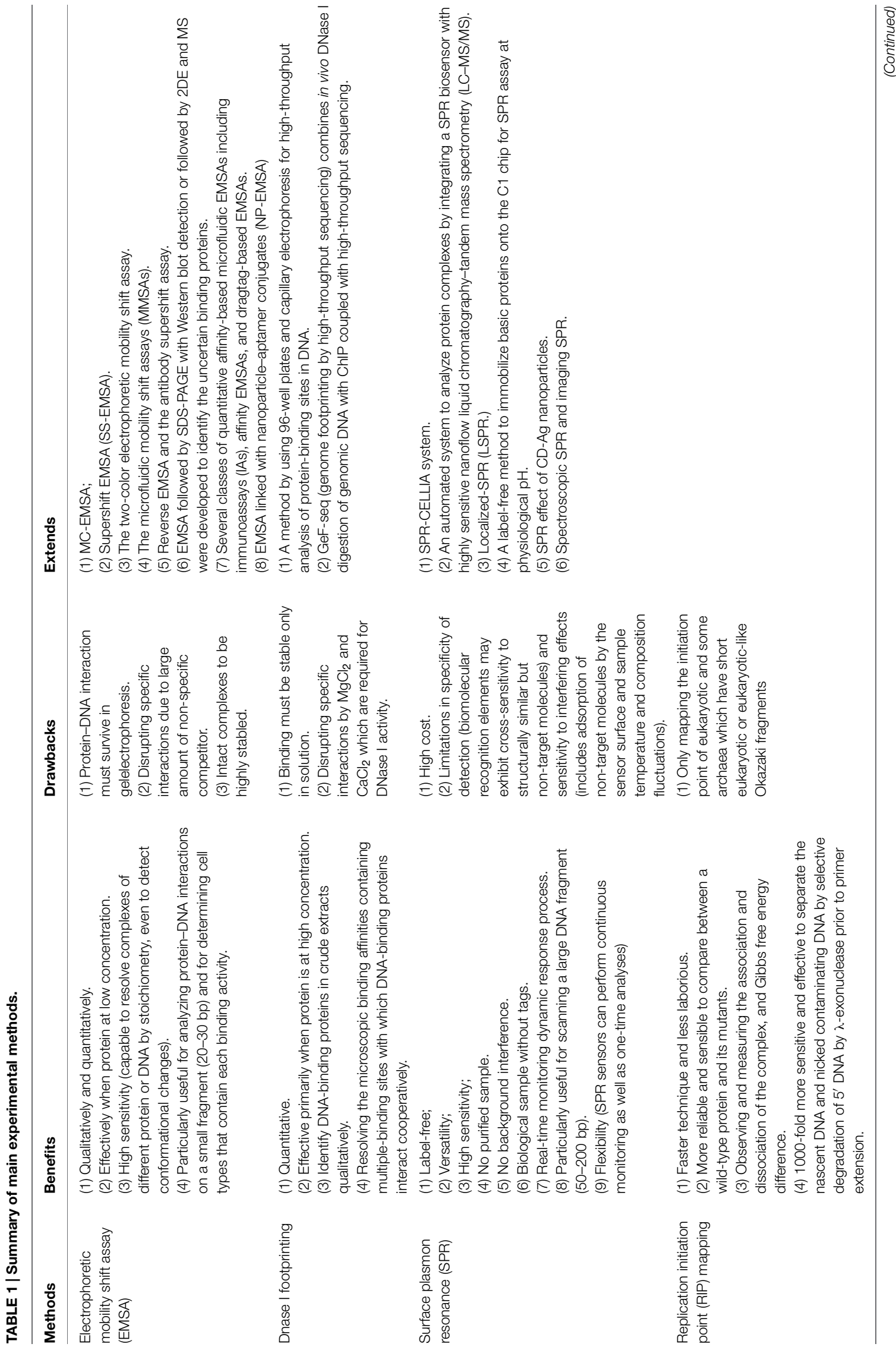

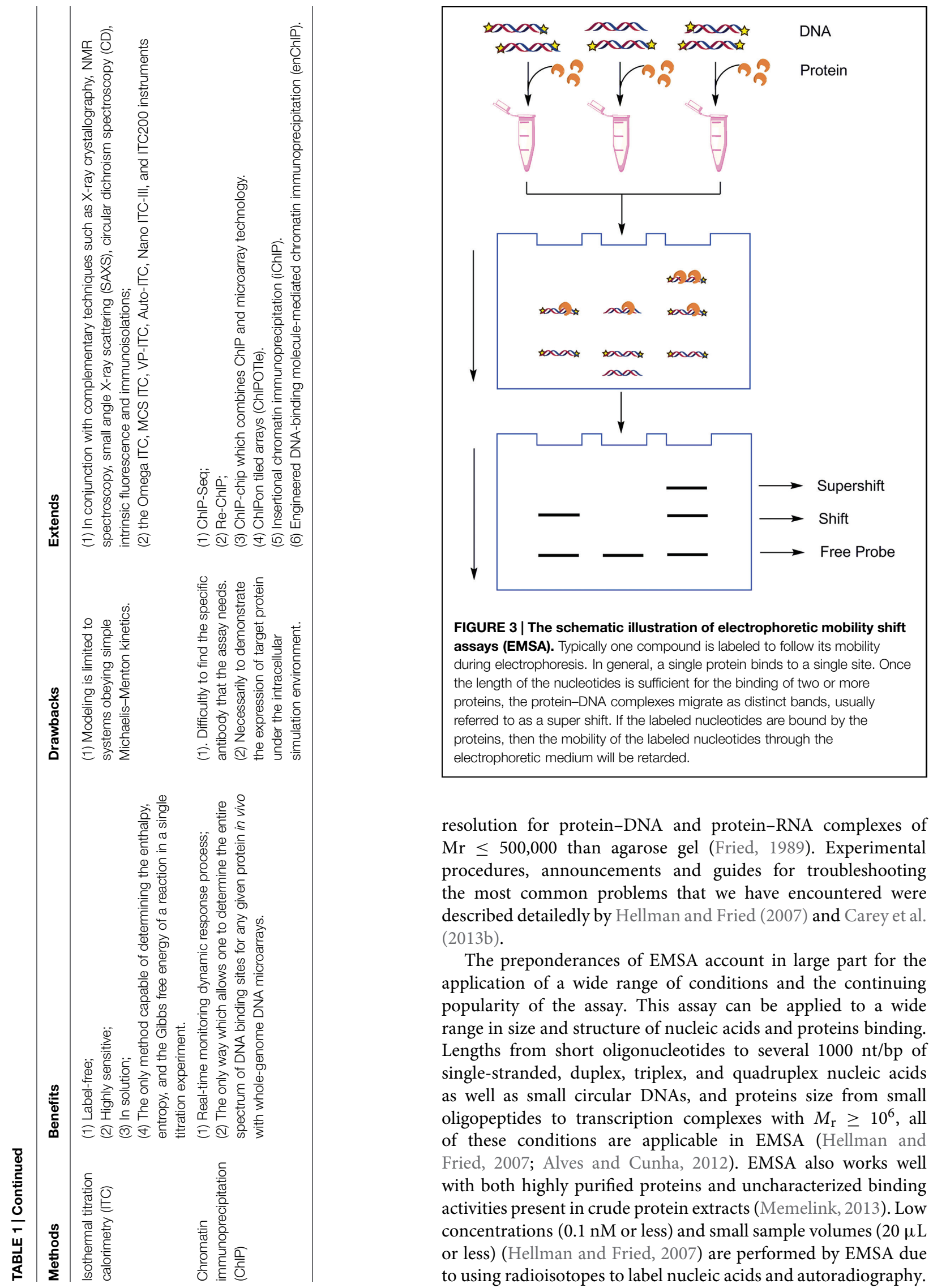

resolution for protein-DNA and protein-RNA complexes of $\mathrm{Mr} \leq 500,000$ than agarose gel (Fried, 1989). Experimental procedures, announcements and guides for troubleshooting the most common problems that we have encountered were described detailedly by Hellman and Fried (2007) and Carey et al. (2013b).

The preponderances of EMSA account in large part for the application of a wide range of conditions and the continuing popularity of the assay. This assay can be applied to a wide range in size and structure of nucleic acids and proteins binding. Lengths from short oligonucleotides to several $1000 \mathrm{nt} / \mathrm{bp}$ of single-stranded, duplex, triplex, and quadruplex nucleic acids as well as small circular DNAs, and proteins size from small oligopeptides to transcription complexes with $M_{\mathrm{r}} \geq 10^{6}$, all of these conditions are applicable in EMSA (Hellman and Fried, 2007; Alves and Cunha, 2012). EMSA also works well with both highly purified proteins and uncharacterized binding activities present in crude protein extracts (Memelink, 2013). Low concentrations ( $0.1 \mathrm{nM}$ or less) and small sample volumes $(20 \mu \mathrm{L}$ or less) (Hellman and Fried, 2007) are performed by EMSA due to using radioisotopes to label nucleic acids and autoradiography. 
Variants or the assay using fluorescence, chemiluminescence, and immunohistochemical detection are also available though less sensitive than radioisotopes.

Since its first publication in 1981, several improvements and variant techniques of EMSA have been developed. Reverse EMSA (rEMSA) and the antibody supershift assay were applied for identifying DNA-protein interactions (Tsai et al., 2012). EMSA followed by SDS-polyacrylamide gel electrophoresis with Western blot detection (Granger-Schnarr et al., 1988; Chen and Chang, 2001) or followed by two-dimensional electrophoresis (2DE) and mass spectrometry (MS) (Woo et al., 2002; Stead et al., 2006) were improved to identify the uncertain binding proteins. The supershift EMSA (SS-EMSA) can identify proteins that carrying a specific epitope in mobilityshifted complex(es) and validate previously identified proteins. Supershift EMSAs suggested the presence of transformationspecific DNA replication complexes in transformed human cells (Di Paola et al., 2010). MC-EMSA is a competition-based method developed by Smith and Humphries (2009) to identify unknown DNA binding proteins incubated with a pool of unlabeled DNA consensus competitors prior to adding the labeled DNA probe. A sensitive two-color EMSA was developed by Jing et al. (2003) for detecting both nucleic acids and protein that either free or bound conditions in gels. This assay is fast, simple, and needless the use of radioisotopes. The microfluidic mobility shift assays (MMSAs) as quantitative EMSA utilize affinity molecular probes (target) to induce a change in analyte molecule size and/or charge (Fourtounis et al., 2011; Karns et al., 2013). Several classes of quantitative affinity-based microfluidic EMSAs including immunoassays (IAs), affinity EMSAs, dragtag-based EMSAs, and other were elaborated by Pan et al. (2014). A separation technique for DNA-protein complex which called microchip electrophoretic mobility shift assay ( $\mu$ EMSA), based on EMSA by microchip electrophoresis was developed by Inoue et al. (2011). The performance of EMSA linked with nanoparticle-aptamer conjugates (NP-EMSA) was improved over the traditional EMSA (Wang and Reed, 2012). The most striking advantages of NPEMSA as described in this research are real-time detection of protein-oligonucleotide interactions, the avoidance of harmful radioisotopes, and elimination of the need for expensive gel imagers.

Electrophoretic mobility shift assays is by far the most frequently used for detecting oriC-DnaA or -oriBPs complexes, ARS-ORC complexes, largely because it is technically the easiest and is often the most sensitive. The proteins which required in EMSA could be obtained from either purified proteins or crude extracts of cells. And the length of target DNA used in EMSA is best less than $300 \mathrm{bp}$. So, the electrophoresis separation effect of probe and protein-DNA complexes will be more obvious. Particularly, EMSA is useful for analyzing proteinDNA interactions on a small fragment (20-30 bp). So, EMSA could be used for identifying the interactions between oriBPs and oriCs, as well as the interactions between oriBPs and single or multiple DnaA boxes (Schaper et al., 2000; Zawilak et al., 2003; Robinson et al., 2004; Pei et al., 2007). For instance, by EMSA, the DnaA of Thermoanaerobacter tengcongensis was detected that it could achieve the efficient binding at a lower protein concentration $(8 \mathrm{nM})$ when the DNA fragment containing two DnaA boxes with 3-bp spacing at $60^{\circ} \mathrm{C}$, and the domain IV of DnaA is thermo-adaptive (Pei et al., 2007). All most the published papers for identifying origins of replication applied EMSA as the basic strategy as well as a standard to determine whether to do the following experiments.

\section{DNase I Footprinting}

The second most common assay is DNase I footprinting, although its use is rapidly declining. The limitation of this method is that it doesn't provide identity of the protein and requires higher concentration protein than EMSA (Leblanc and Moss, 2001). Even so, this method provides a myriad of applications both in determining the site of interaction of most sequence-specific DNA binding proteins and characterizing the binding interactions. The protein-DNA complexes are separated from free (unbound) DNA relies on a change that the protein prevents binding of DNase I in and around its binding site and thus generates a "footprint" in the cleavage ladder in denaturing acrylamide gel (shown in Figure 4). The distance from the end label to the edges of the footprint represents the position of the protein-binding site on the DNA fragment. In addition of DNase $\mathrm{I}$, the enzymatic digestion methods also include the use of MNase (Fox and Waring, 1987), methidiumpropyl-EDTA_Fe(II) (MPE) (Van Dyke and Dervan, 1983), copper phenanthroline, uranyl photocleavage, hydroxyl radicals, DMS, and iron complexes (Dey et al., 2012). The classic experimental procedure, recipes, and consideration were detailed by Carey et al. (2013a). Recently, DNase I footprinting assay with fluorescent 6-carboxyfluorescein (FAM)-labeled probes was widely used for identifying the correct nucleotides regions that proteins protected (Zianni et al., 2006). The use of FAM-labeled primers eliminates the need for radioactively labeled nucleotides, slab gel electrophoresis, as well as commonly available automated fluorescent capillary electrophoresis instruments. The result of Thermo Sequenase outputted by Genemapper software was accurately aligned with DNase I digestion products, providing a ready means to assign correct nucleotides to each peak from the DNA footprint. Genome Footprinting by high-throughput sequencing (GeF-seq) was proved powerful to elucidate the molecular mechanism of target protein binding to its cognate DNA sequences (Chumsakul et al., 2013). In this research, GeF-seq combines in vivo DNase I digestion of genomic DNA with ChIP coupled with highthroughput sequencing.

Different with EMSA, DNase I footprinting is useful for scanning a large DNA fragment (50-200 bp) for DNA-protein interaction. Mostly, DNase I footprint assay was used for initially identifying the location and number of DnaA boxes from the whole region of oriC after EMSA. Through high-throughput analysis, the sequences of DnaA boxes could be confirmed and analyzed. DNase I footprinting widely applied in identification of oriCs in bacteria and archaea. The two oriCs of S. solfataricus have been identified before, DNase I footprinting assay has been fully used in the study (Robinson et al., 2004). Through DNase I footprinting, the precise sequences and locations of ORBs (origin recognition boxes) in oriC1 and oriC2 of $S$. Solfataricus which bind to three Orc1/Cdc6s have been directly 


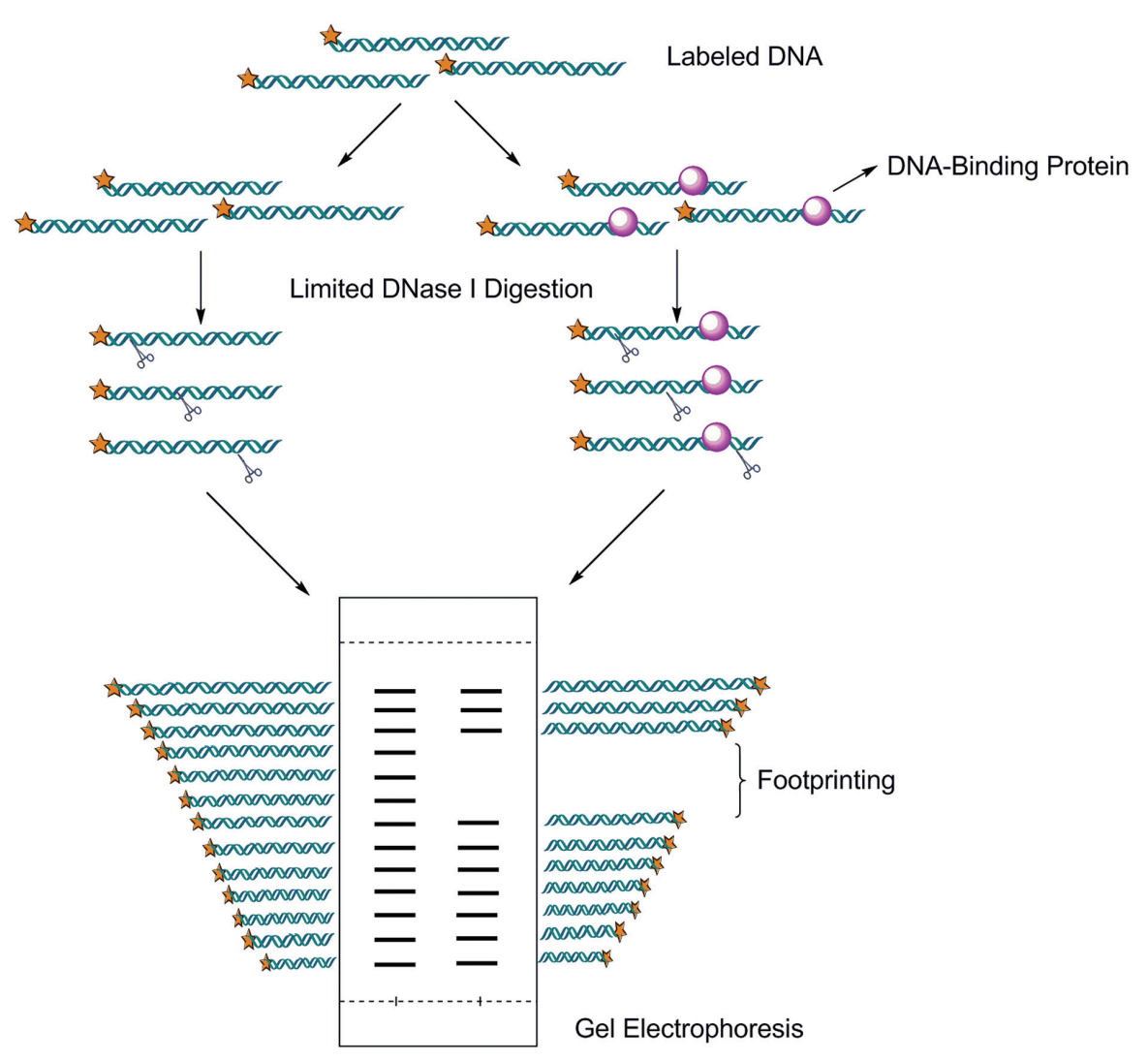

FIGURE 4 | Dnase I footprinting. This Analysis involves endonuclease treatment of an end labeled DNA fragment bound to a protein. This technique relies on the fact that fragments of DNA that have DNA-binding proteins bound will move more slowly through an acrlyamide gel. The enzyme DNasel will only cut exposed DNA. Limited digestion yields fragments terminating everywhere except in the footprint region, which is protected from digestion.

identified, respectively. DNase I footprinting was also used for the identification oriCs of E. coli (Fuller et al., 1984), Pyrococcus furiosus (Robinson et al., 2004), and Caulobacter crescentus (Taylor et al., 2011). So, DNase I footprinting is one of the most useful method for identifying replication origins in microbial genomes.

\section{Surface Plasmon Resonance}

Since the SPR (surface plasmon resonance) technology was first used in chemical sensors, SPR sensors have gradually become an emerging alternative to the conventional in vitro techniques to study DNA-protein interactions, due to its label-free, high-sensitivity, real-time analysis, and flexible system design (Liedberg et al., 1995; Homola et al., 1999; Ladd et al., 2009). Figure 5 depicts the basic principle and schematic illustration of SPR system. Compared to other methods studying protein interaction, such as direct protein interaction in vitro and coimmunoprecipitation, SPR is a more sensitive and quantitative biophysical approach that can measure binding affinity and kinetics simultaneously (Hoa et al., 2007). Furthermore, this technique is the basis of many lab-on-a-chip and biosensor applications. According to recent research, SPR technology can be particularly used to study the interactions between nucleic acids or protein-nucleic acids by real-time tracking of the nucleic acid reaction process. This application of SPR is unmatched by other techniques (Pattnaik, 2005; Sahai, 2011). The stoichiometry and kinetics of complex formation between DnaA protein and ori $C$ could be analyzed using SPR experiments.

Surface plasmon resonance technique is an optical method for measuring the refractive index of very thin layers of material adsorbed on a metal. Its development will further extend the potential of SPR-sensing technology and allow SPR sensors to be used far more widely. Spectroscopic SPR and imaging SPR have been further adapted as affinity detection techniques in the proteomic and genomic fields, especially in a protein conformation study (Despeyroux et al., 2000), biomarker profiling, aptamer selections (Murphy et al., 2003), and antibody selections (Wilson and Howell, 2002). SPR-CELLIA system was configured for either whole cells or macromolecules in two parallel flow paths (Baird and Myszka, 2001). Applied Biosystems has also launched Affinity Sensor instrument based on SPR technology (Pattnaik, 2005). An automated system which developed for analyzing protein complexes by coupling a polymerization initiator to a biospecific interaction and inducing inline atom transfer radical polymerization (ATRP) was developed with highly sensitive nanoflow liquid chromatography-tandem mass spectrometry (LC-MS/MS) (Liu et al., 2010). Nanomaterials developed for localized surface 


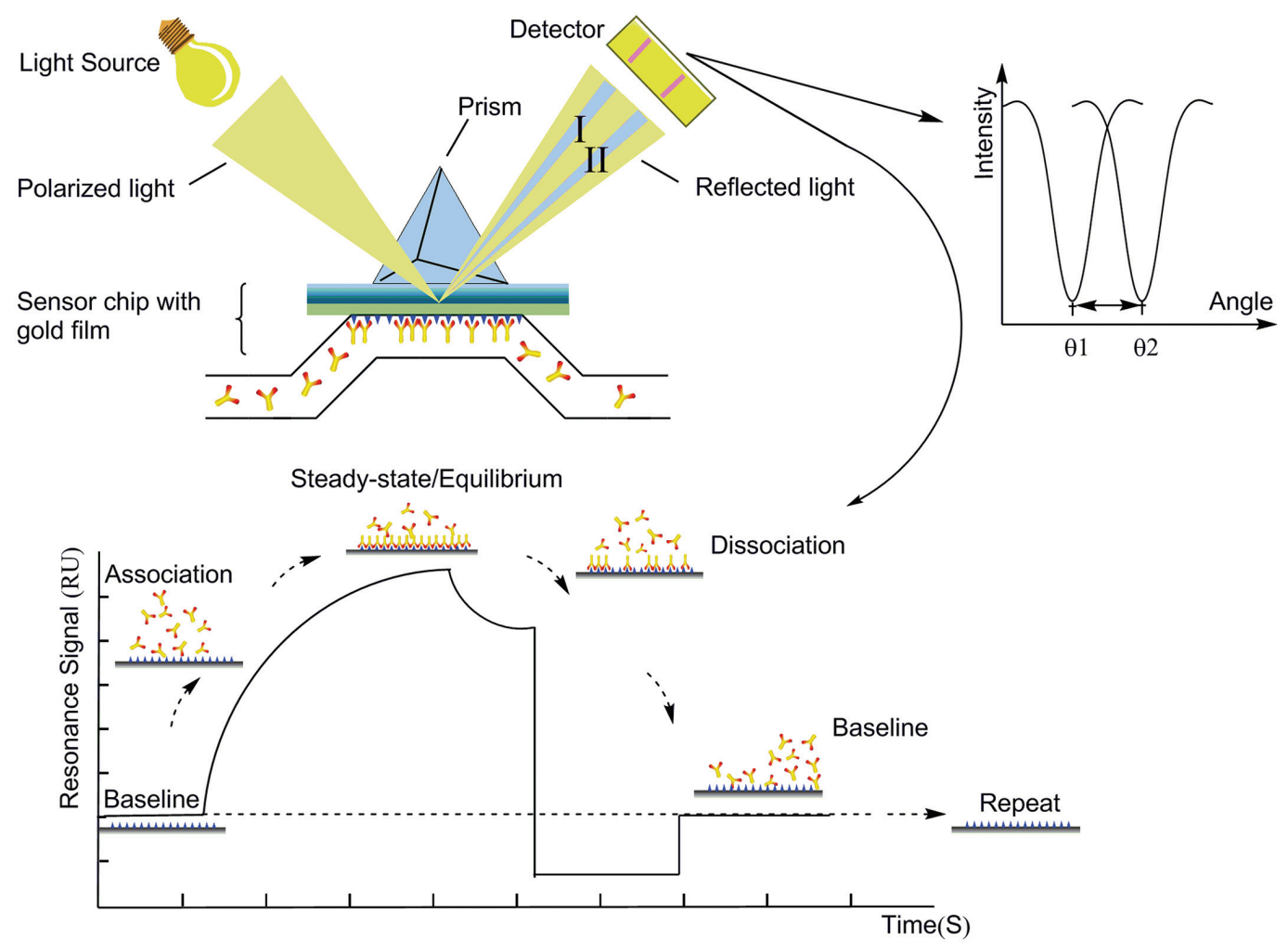

FIGURE 5 | The schematic illustration of surface plasmon resonance (SPR) system. SPR detects changes in the refractive index in the immediate vicinity of the surface layer of a sensor chip. The sensor surface is gold with antibodies attached to it. During the measurement, the chip is irradiated from the bottom with a beam of a wide angle range within that of total internal reflection. The SPR angle shifts (from I to II in the diagram) when biomolecules binding events cause changes in the refractive index at the surface layer. The detector will determine the angle of the intensity decrease. This change in resonant angle can be monitored non-invasively in real time as a plot of resonance signal (proportional to mass change) versus time (Sawhney and Singh, 2000; Cooper, 2002; Pattnaik, 2005; Sahai, 2011; Hou and Cronin, 2013).

plasmon resonance (LSPR) are increasingly integrated to classical prism-based SPR sensors, providing enhanced sensitivity and lower detection limits (Bolduc and Masson, 2011). Khan et al. developed a label-free method to immobilize basic proteins onto the $\mathrm{C} 1$ chip for SPR assay at physiological $\mathrm{pH}$, which presents ligand with less conformational modification and thereby maintains the ligand at optimal biological activity (Khan et al., 2012). Besides, some materials have been proposed to improve the performance of SPR biosensors, such as gold nanoparticles, magnetic nanoparticles (MNP), carbon nanotubes, electropolymerized molecularly imprinted polythiophenes (Lyon et al., 1998; Wang, 2005; Parab et al., 2010; Pernites et al., 2010; Špringer et al., 2014).

Surface plasmon resonance-based biosensing is one of the most advanced label free, real time detection technologies. But, one of the main drawbacks that stem further development of SPR applications is the lack of sufficient sensitivity to reliably detect small changes in refractive index caused by compounds with low molecular weight or in low concentration at the sensing surface (Wang, 2005). So, several approaches have been reported to resolve such limitations. A modified SPR device achieved that the plasmonic detected single molecules in real time without the need for labeling or amplification by using a gold nanorod. And, the sensitivity of this device is $\sim 700$ times higher than state-of-theart plasmon sensors (Zijlstra et al., 2012). A new approach to SPR biosensors for rapid and highly sensitive detection of bacterial pathogens is based on the spectroscopy of grating-coupled longrange surface plasmons (LRSPs) combined with MNP assay (Wang et al., 2012). A highly efficient SPR immunosensor was effectively enhanced the sensitivity by using a non-covalently functionalized single graphene layer on a thin gold film (Singh et al., 2015).

DNA fragments were immobilized on a streptavidin matrix coated sensor chip by biotin covalent linkage. SPR analysis was performed by injecting solutions of replication origin protein from targeted bacteria or archaea followed by injection of replication origin protein from other bacteria or archaea for comparison (Jiang et al., 2003; Pei et al., 2007). Also, we can use SPR for analyzing the binding reactions of ATP- and ADPDnaA protein to the oriC regions (Schaper et al., 2000; Pei et al., 2007). Based on the difference functions of ATP and ADP, the result revealed that DnaA proteins require ATP for sitespecific unwinding at $T$. tengcongensis oriC region (Pei et al., 2007). Similar result was obtained in Thermus thermophilus (Schaper et al., 2000). This is similar to those in E. coli and T. maritima, further supporting that the ATP dependent 
activation of DnaA in replication initiation is highly conserved in bacteria. The study of S. solfataricus eukaryote-like Orc1/Cdc6 initiators interacting with DNA polymerase B1 (Zhang et al., 2009) and $T$. tengcongensis DnaA initiators interacting with anti-terminator NusG (Liu et al., 2008) also profited from the widespread use of SPR. Messer et al. (2001) studied DnaA rules for DnaA binding and roles of DnaA in origin unwinding and helicase loading by SPR.

\section{Replication Initiation Point mapping}

Replication initiation point mapping method was developed by Gerbi and Bielinsky (1997) and Bielinsky and Gerbi (1998) to identify the RIPs by using the symmetry of a typical replication bubble that emerges once the bidirectionally moving forks have been established. This technique has been successfully used to detect the initiation sites of DNA replication (even locations of each DnaA box) at the nucleotide level in chromosomes (Matsunaga et al., 2003; Robinson et al., 2004; Pei et al., 2007) or plasmid (Sun et al., 2006) in many organisms. RIP mapping utilizes the shortest lengths of eukaryotic Okazaki fragments to map the transition point between leading and lagging strand synthesis by extending primers to various initiation points in an asynchronous population of replicating molecules schematic illustration (as shown in Figure 6). The extension products are fractionated on sequencing gels finally where maps that leading strand synthesis starts at a unique site, in both small and large origins.

Replication initiation point mapping is 1000-fold more sensitive and more effective to separate the nascent DNA and nicked contaminating DNA by selective degradation of $5^{\prime}$ DNA by $\lambda$-exonuclease prior to primer extension (Gerbi and Bielinsky, 1997) which ensures the integrity of RNA-primed DNA. Incipiently, this technology was used to identify the RIP of Eukaryote. Recently, works were demonstrated that archaea also have short eukaryotic-like Okazaki fragments allowing this technique to be used to map the initiation point of $P$. abyssi (Matsunaga et al., 2003). Robinson et al. (2004) performed RIP mapping to identify two origins of replication (oriC1 and the Cdc6-3 proximal origin-oriC2) in the single chromosome of the hyperthermophilic archaeon S. solfataricus. RIP mapping confirmed that the autonomously replicating sequence (ARS) elements corresponding to each replicon were functional in the chromosomal context of the halophilic archaeon Haloferax volcanii (Norais et al., 2007). But, because the exact size of the RNA primer synthesized by archaeon primase in vivo is not known, this technique does not allow the identification of the precise nucleotide at which replication initiates in archaeon that have multi-oriCs.

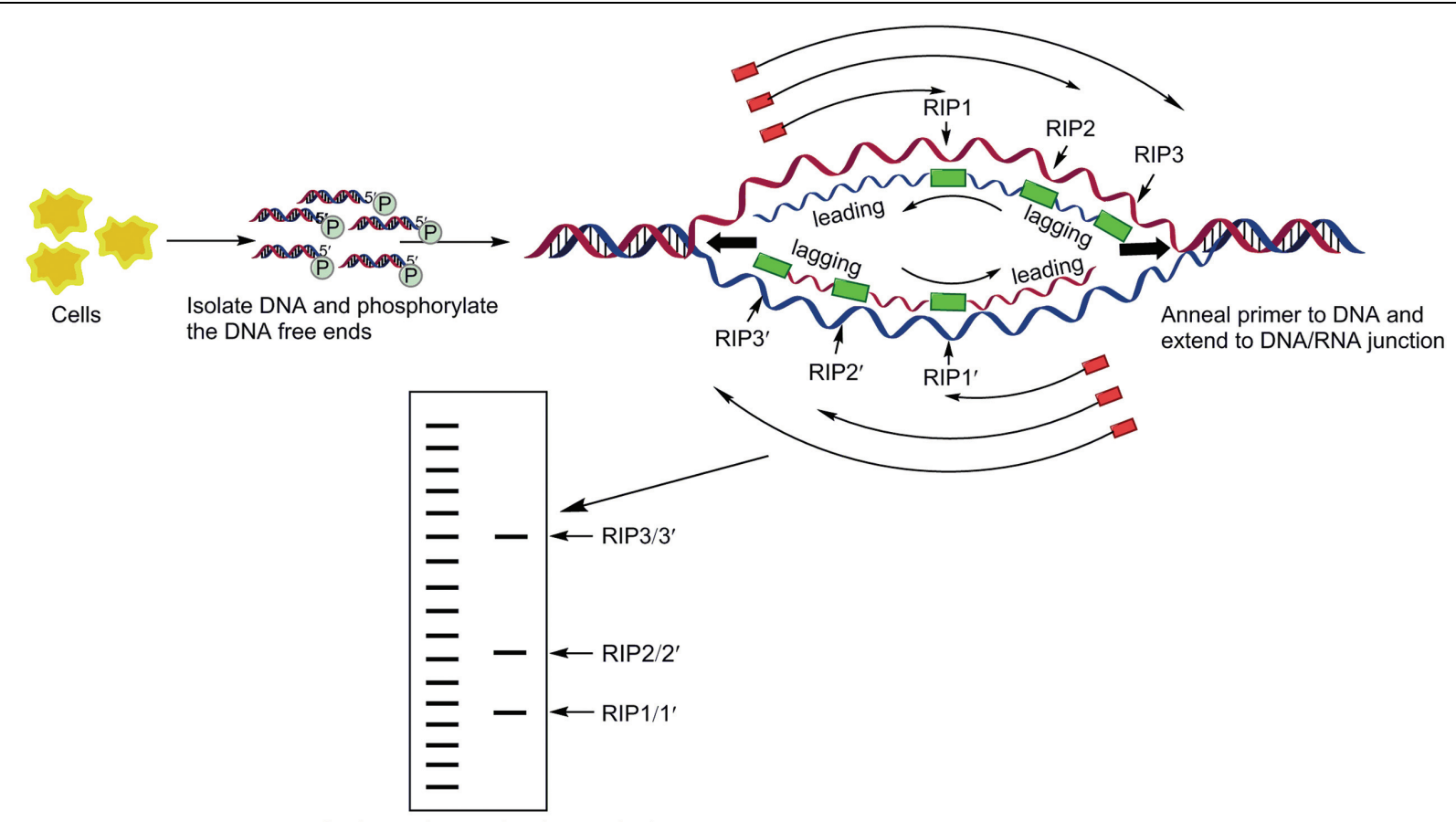

Analyze primer extension products on a sequencing gel

FIGURE 6 | Replication initiation point (RIP) mapping. The replication bubble of semi-discontinuous replication is diagrammed here. After phosphorylation of any $5^{\prime}-\mathrm{OH}$ ends with polynucleotide kinase, replication intermediates enriched on the BND-cellulose column are treated with $\lambda$-exonuclease to digest nicked DNA. Digestion is confirmed on the agarose gel before proceeding to the primer extension reaction. The primer extension products are showed as arrows outside the replication bubble, stopping at DNA/RNA junctions on the DNA. Extension stops at the points labeled RIP1, RIP2, RIP3. Green rectangles depict the RNA primers of nascent strands. PCR products are purified and analyzed on a denaturing polyacrylamide gel. Due to asynchrony, the replication bubble can be of various sizes, resulting in various length, is the transition point from discontinuous to continunous synthesis. Sequencing and RIP reactions were analyzed side by side on the same gel (Gerbi and Bielinsky, 1997; Matsunaga et al., 2003; Lee and Romero, 2012). 


\section{Isothermal Titration Calorimetry}

Isothermal titration calorimetry is a label-free, powerful, and highly sensitive technique for studying molecular interactions in solution. This method has been applied quite extensively to investigate the interaction of a macromolecule (in general, a protein) with small ligands (Sigurskjold, 2000; VelazquezCampoy and Freire, 2006), other proteins (Pierce et al., 1999; Velazquez-Campoy et al., 2004), and nucleic acids (Matulis et al., 2000) as well as with drugs (Ward and Holdgate, 2001; Boonsongrit et al., 2008) and metal ions (Zhang et al., 2000), relies on the fact that such an interaction is accompanied by a heat effect. It does not rely on the presence of chromophores or fluorophores, nor does it require an enzymatic assay. A number of parameters such as enthalpy of binding $(\Delta \mathrm{H})$, entropy of binding $(\Delta S)$, association constant $(\mathrm{Ka})$, binding stoichiometry $(\mathrm{n})$, free energy of binding $(\Delta G)$, and potential site-site interactions (cooperativity) can be obtained from a single calorimetric titration, providing a full thermodynamic description of an interacting system (Figure 7).

Isothermal titration calorimetry has been one of the most common tools used for investigating interactions of protein association with nucleic acids. Recent advances in ITC instrumentation and data analysis software like the Omega ITC, MCS ITC, VP-ITC, Auto-ITC, Nano ITC-III, and ITC200 instruments have facilitated the development of experimental designs. It also can provide an informative thermodynamic when used in conjunction with complementary techniques such as X-ray crystallography, NMR spectroscopy, small angle $\mathrm{x}$-ray scattering (SAXS), circular dichroism spectroscopy (CD), intrinsic fluorescence, and immunoisolations. Many particularly interesting reports employ ITC, with a focus on protein interactions with nucleic acids. Zhou et al. (2008) have utilized ITC in their study of the role of $E$. coli proline utilization A (PutA) flavoprotein, which acts as the transcriptional repressor of proline utilization genes putA and putP. ITC of PutA binding to the optimal oligonucleotide $(\mathrm{O} 2)$ revealed a strongly endothermic interaction in Tris buffer but a weakly exothermic interaction in phosphate buffer. Kozlov and Lohman (2012) employed ITC to analyze the interaction about $E$. coli SSB and $D$. radiodurans SSB binding to ssDNA, respectively. Crane-Robinson et al. (2009) and Gilbert and Batey (2009) present an overview of ITC experiments on protein/DNA complexes, with detailed descriptions of the experimental methodologies. This review concentrates on the thermodynamics of interaction of protein DNA binding domains with DNA duplexes, and gives a thorough description of the joint implementation of ITC and differential scanning calorimetry (DSC) to provide a thorough description of the binding process. In spite of the widely using, there remain some important points to the use of ITC that should always be considered. Just as Falconer said in two reviews about ITC (Falconer et al., 2010; Falconer and Collins, 2011), several aspects of ITC data collection have been outlined in the reviews.

As more and more correlative analyses are performed and databases increased their informative capacity, ITC

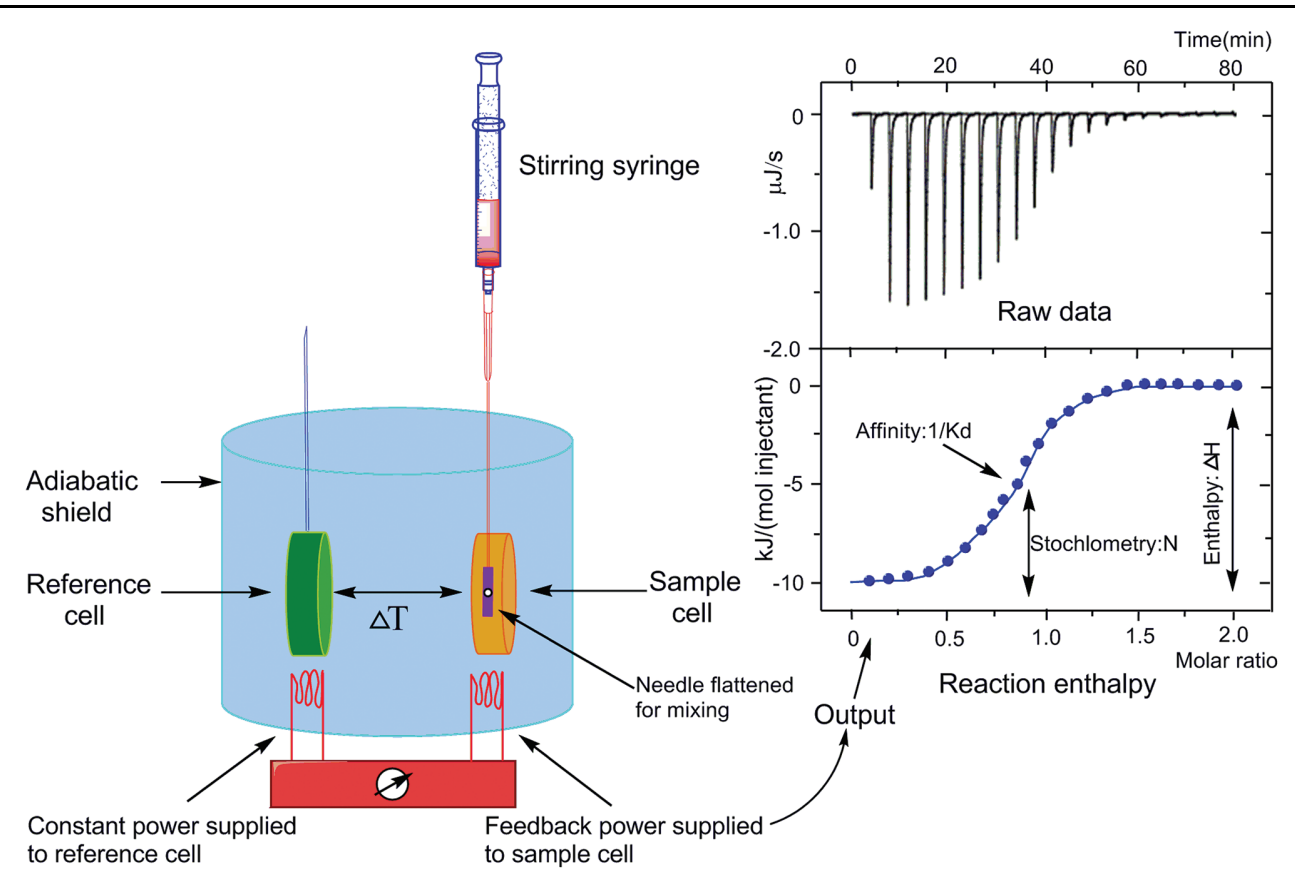

FIGURE 7 | Basic principle of isothermal titration calorimetry. Schematic representation of the isothermal titration calorimeter (left) and a characteristic titration experiment (upper right) with its evaluation (lower right). In (upper right) picture, the titration thermogram is represented as heat per unit of time released after each injection of the ligand into the protein (black), as well as the dilution of ligand into buffer (blue). In (lower right) picture, the dependence of released heat in each injection versus the ratio between total ligand concentration and total protein concentration is represented. Circles represent experimental data and the line corresponds to the best fitting to a model considering $n$ identical and independent sites. The syringe is inserted in the sample cell and a series of injections are made (Freyer and Lewis, 2008; Martinez et al., 2013). 
should develop more accurate and powerful for estimating binding affinities from known structures and conversely to use thermodynamic data to make informed predictions regarding the properties of molecular interfaces. Although ITC is widely used in identification of protein-DNA interaction, the using in identification of replication origins is vacant.

\section{Conventional Methods for Detecting Protein-DNA Interaction at Origins of Replication In Vivo}

\section{Chromatin Immunoprecipitation}

Chromatin Immunoprecipitation is an excellent experimental method to determine the interactions of proteins with their binding sites in vivo. This technique is frequently used to detect the interactions between DnaA or oriBPs and replication origins due to the ability that ChIP assays allow one to determine the entire spectrum of DNA binding sites for any given protein in vivo with whole-genome DNA microarrays. ChIP also could be used for determining whether there were changes in the levels of binding oriCs and DnaA during different cell-cycle phase in vivo (Robinson et al., 2004; Duggin et al., 2008). As described in many papers, living cells should be handled with chemical cross-linkers to covalently bind proteins with each other and then with their DNA targets. Once cross-linked to associated proteins, sonication is used to extract and fragment chromatin, and specific antibodies against a target protein is employed to isolate protein-DNA complexes. The cross-links that is binding with proteins and
DNA are then reversed, and the associated DNA was subjected to qPCR analysis to test for coprecipitation of specific DNA sequences (Orlando, 2000; Buck and Lieb, 2004). Using specific antibody or several antibodies together is one of key steps in ChIP assay. Antisera was obtained through recognizing one major chromatin associated band of approximately expected molecular weight in cell-free extracts of Pyrococcus furiosus (Komori and Ishino, 2001), S. solfataricus (Robinson et al., 2004), C. crescentus (Gorbatyuk and Marczynski, 2005; Taylor et al., 2011), and Pyrococcus abyssi (Matsunaga et al., 2001, 2007). The anti-DnaA antibody of E. coli (Sekimizu et al., 1988; Newman and Crooke, 2000) and Bacillus subtilis (Ogura et al., 2001; Gorbatyuk and Marczynski, 2005) was obtained by the same way. In a study of the identification of the the chromosomal dif site that binds Xer in S. solfataricus in vivo via ChIP and ChIP-chip, the antibodies required in ChIP assay were affinity purified from antisera that were raised against Xer-6H (His6-tagged Xer) in rabbits using Xer-6H immobilized on an NHS-activated agarose Hi-Trap column (GE Healthcare) (Duggin et al., 2011). The basic method is shown in Figure 8.

Despite the tremendous value of ChIP methods, it is important to be aware of their limitations. Carey et al. (2009) has listed three limitations of 'standard' ChIP experiment: (1) The ChIP assay often yields low signals in comparison to negative controls, which can lead to inconclusive results; (2) it is difficult to determine the precise binding site for a factor because of the limited resolution of the assay; and (3) ChIP is not a functional assay and cannot by itself demonstrate the functional significance of a protein or modified histone found to be located at a genomic

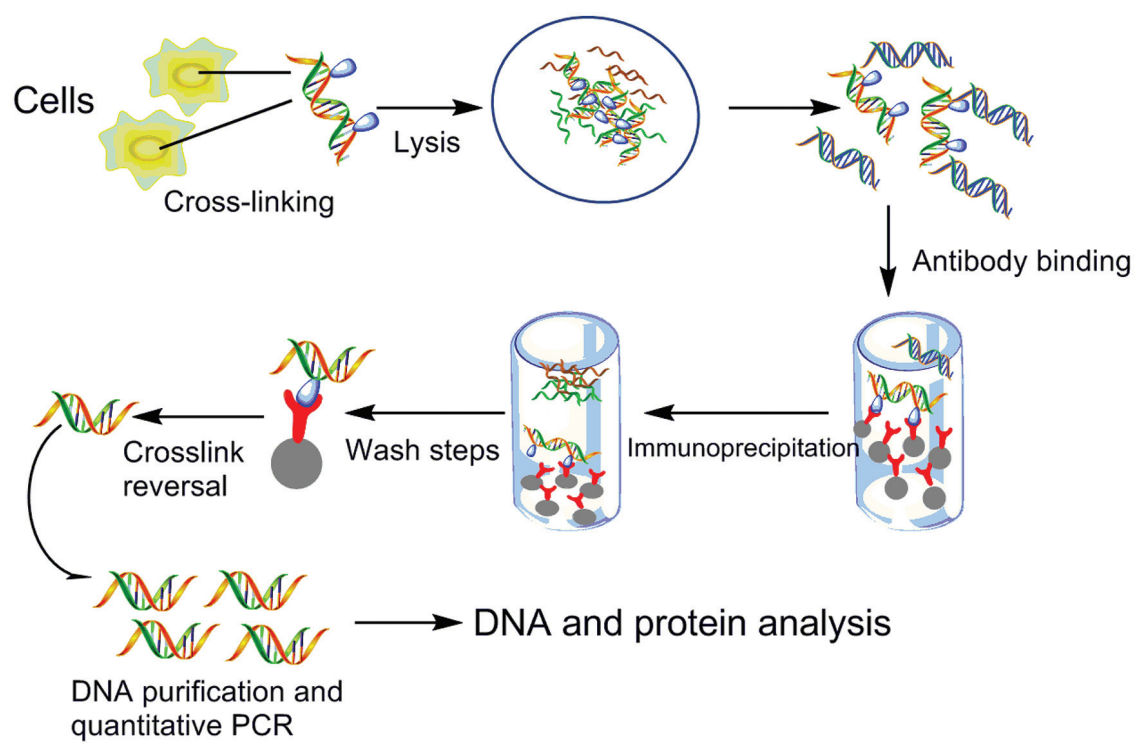

FIGURE 8 | Chromatin immunoprecipitation. Protein and associated chromatin in living cells or tissues are temporarily bonded, the DNA-protein complexes (chromatin-protein) are then sheared into 500 bp DNA fragments using either enzymatic digestion or physical shearing by sonication. Cross-linked DNA fragments associated with the protein(s) of interest using formaldehyde are selectively immunoprecipitated from the cell debris using appropriate protein-specific antibody. After the cross-links are reversed, the associated DNA fragments are purified and their sequence is determined. These DNA sequences are supposed to be associated with the protein of interest in vivo. The DNA undergoes PCR amplification using primers targeting a particular genomic locus. These DNA sequences can be subjected to a number of downstream analysis techniques, including targeted approaches, like semiquantitative PCR and quantitative PCR, and genome-wide analyses using microarrays (ChIP-chip) and deep sequencing (ChIP-seq), ChIP-on-chip (Shah, 2009; Vinckevicius and Chakravarti, 2012). 
region of interest. Recent advances in ChIP methodology have overcome some of the limitations, and the development of complementary assays, and analyses have expanded the number, types and resolution of protein-DNA interactions that have been discovered. Such as ChIP-chip (Horak and Snyder, 2002; Buck and Lieb, 2004), ChIP on tiled arrays (ChIPOTle) (Buck et al., 2005), ChIP-Seq (Robertson et al., 2007; Schmidt et al., 2009), ChIP-PaM (Wu et al., 2010), Re-ChIP (Truax and Greer, 2012) were developed for analyzing the more specific interactions between protein and DNA sequences. By means of ChIP coupled with hybridization on a whole genome microarray (ChIP-chip), researchers detected the binding of Cdc6/Orc1 to oriC of archaeon $P$. abyssi in vivo. And it was the first time that ChIP-chip method used for identifying the genome-wide distribution of the initiator of DNA replication in Archaea and Bacteria (Matsunaga et al., 2007). ChIP-on-chip was widely applied to genome-wide analysis, which combines the specificity of ChIP with the unbiased, high-throughput capabilities of microarrays (Testa et al., 2005; Huebert et al., 2006; Wyrick et al., 2009; Kim et al., 2014). Isolation of specific genomic regions retaining molecular interactions is necessary for their biochemical analysis. Insertional ChIP (iChIP) was a useful tool for dissecting chromatin structure of genomic region of interest. This technique can efficiently isolate of specific genomic domains (Hoshino and Fujii, 2009). In addition, a novel method called engineered DNA-binding molecule-mediated chromatin immunoprecipitation (enChIP) was established, for purification of specific genomic regions retaining molecular interactions (Fujita et al., 2013). Here, we detailed analyze ChIP-seq.

\section{ChIP Sequencing}

Chromatin immunoprecipitation coupled with microarrays (ChIP-chip) or short-tag sequencing (ChIP-seq) has become the standard technique for identifying the locations and biochemical modifications of bound proteins genome-wide. ChIP-seq can be done without prior knowledge of the underlying sequence and relies only on the subsequent DNA sequence alignment to the reference genome of interest Compared to ChIP-chip. Furthermore, the nature of the microarray hybridization signal makes detection and rigorous quantification of low abundance signals problematic. Taken together, ChIP-seq can provide greater resolution, sensitivity, and specificity compared to ChIP-chip (Johnson et al., 2007; Robertson et al., 2007; Schmidt et al., 2009). Owing to the tremendous progress in next-generation sequencing technology including the Genome Analyzer (Illumina, formerly Solexa), SOLiD (Applied Biosystems), 454-FLX (Roche), and HeliScope (Helicos) (Morozova and Marra, 2008; Schmidt et al., 2009), ChIP-seq offers higher resolution, less noise, and greater coverage than its array-based predecessor ChIP-chip. With the decreasing cost of sequencing, ChIP-seq has become an indispensable tool for studying gene regulation and epigenetic mechanisms.

ChIP-seq experiments generate large quantities of data, and effective computational analysis will be crucial for uncovering biological mechanisms. An important consideration in experimental design is the minimum number of sequenced reads required to obtain statistically significant results. The standards and guidelines for carrying out ChIP-seq has been described based on the collective experience of laboratories involved in the Encyclopedia of DNA Elements (ENCODE) and model organism ENCODE (modENCODE) projects, including antibody validation, choosing appropriate sequencing depth, experimental replication, data quality assessment, data and metadata reporting (Landt et al., 2012). However, ChIP-seq has been proved to be a potential tool in the study of histone modifications, nucleosome positioning, and mapping of binding sites of various DNA binding proteins. Certainly, there are more and more researchers used ChIP coupled with high-throughput sequencing (ChIP-seq) to identify replication origins precisely, especially for the yeast genome or other eukaryotes (Eaton et al., 2010, 2011; Gilbert, 2010; Martin et al., 2011). Using ChIP or ChIP-seq, we can capture the change of DnaA protein level in the whole replication process of cells in vivo.

\section{Other Methods and Applications}

In addition to the methods described here, many methods were developed to identify the majority of origins found in the previous report. Complements and extends were achieved by direct, high resolution mapping of potential origins and proteins that could bind with the specific sites in the origins of replication, also something related to replication origins.

Owing to the pivotal role played by DNA-associating proteins in various cellular processes, many in vitro, in vivo, in silico, and biophysical techniques have been developed to study DNAprotein interactions. In vitro technique includes southwestern assay, yeast one-hybrid assay $(\mathrm{Y} 1 \mathrm{H})$, phage display and proximity ligation assay (PLA); scanning probe microscope (SPM) is a novel in vivo method on the interaction of protein-DNA; biophysical technique includes many methods, such as fluorescencebased techniques [time-resolved fluorescence depolarization, double labeled native gel electrophoresis and fluorescencebased imaging, fluorescence resonance energy transfer (FRET) techniques (Clegg, 1995)], capillary electrophoresis with laserinduced fluorescence (CE-LIF) (Riddick and Brumley, 2008), also some fluorescence-based protein or nucleic acids bioprobe like FRep (Shahravan et al., 2011), quantum dots (QDs) (Michalet et al., 2005), SPR, nuclear magnetic resonance, circular dichroism (CD), atomic force microscopy (AFM), and microcalorimetry (Dey et al., 2012).

ARS (autonomously replicating sequence) assays first utilized to prove that DNA sequences was important for replication by determining whether a given DNA fragment initiates replication when placed on a plasmid in yeast (Struhl et al., 1979). The plasmid-based ARS assay was used to identify numerous replication origins in budding and fission yeasts (Newlon, 1996; Huberman, 1999). PCR-based assay which is an alternative approach to the plasmid-based ARS assay was utilized to identify replicator at ectopic sites in the genome (Malott and Leffak, 1999; Vernis et al., 1999; Tao et al., 2000). In 1996, EMSA and DNase I footprint analysis were employed to detect the interaction of the IciA protein which is known to bind to the AT-rich repeat region in the E. coli origin of chromosome replication, with AT-rich regions in replication origins of plasmids F and R1 (Wei and Bernander, 1996). The direction of 
replication fork movement is ascertained to pinpoint the origin located between the outwardly moving forks by neutral/alkaline gel electrophoresis (Nawotka and Huberman, 1988). Patrizia Contursi first described the functional cloning of a chromosomal oriC of the hyperthermophilic archaeon S. solfataricus from an archaeon and confirmed the proposed location by 2-D gel electrophoresis experiments. As described in the study, it represented an important step toward the reconstitution of an archaeal in vitro DNA replication system (Contursi et al., 2004). 2D neutral-neutral agarose gel analysis was used to test whether the loci associated with the cdc6 genes in the single chromosome of $S$. solfataricus might contain origins of replication (Robinson et al., 2004). Due to DNA isolated from asynchronously replicating cells and subjected the DNA to digestion with restriction enzymes, this technique can detect replication intermediates directly corresponding to the resolution of distinct arcs on the gel. Furthermore, RIP mapping was used to identify the RIPs at both origins in S. solfataricus and DNase I footprinting analysis, ChIP, EMSA were all utilized frequently to detect whether the Cdc6 could bind to the both origins in this study (Robinson et al., 2004). Zawilak et al. (2003) have presented the DNA recognition properties of the $H$. pylori DnaA protein. The interactions between the purified DnaA protein of $H$. pylori and its target were analyzed by gel retardation assay and SPR in vitro. A series of competition gel retardation assays were performed to elucidate the binding requirements and analyze the DNA-protein complexes (Zawilak et al., 2003). In the study of mechanism for the DnaA-oriC cooperative interaction at high temperature and duplex opening at an unusual AT-rich region in T. tengcongensis, many techniques for studying the interaction of protein-DNA complexes were utilized for different purposes. The GAL4-based yeast twohybrid system, EMSA, RIP mapping, open-complex formation assay, SPR, nuclease P1 assay were used in this research for different interactions of protein-DNA complexes. It's proud that it's the first experimental demonstration of the chromosomal RIP in thermophilic bacteria at nucleotide level (Pei et al., 2007).

In the study of interactions of DnaA proteins from distantly related bacteria with the replication origin of the broad host range plasmid RK2, DNase I footprinting, gel mobility shift, and SPR analyses were utilized to compare the interactions of oriV with five different DnaA proteins from E. coli, Pseudomonas putida, Pseudomonas aeruginosa, B. subtilis, and Streptomyces lividans (Caspi et al., 2000). The results revealed that the DnaA proteins of a host bacterium were incapable to form a stable and functional complex with the DnaA boxes at oriV is a limiting step for plasmid host range (Caspi et al., 2000). Mode of initiator-oriC interactions with the loop formation between the subcomplexes of the discontinuous origin of H. pylori was revealed by the experimental analysis of RIP mapping, electron microscopy, and immunoprecipitation assay. H. pylori oriC exhibited bipartite structure and being the first such origin discovered in a Gram-negative bacterium (Donczew et al., 2012). Katarzyna et al. (2014) used SPR and EMSA methods to measure the sequence-specific interactions of Rep proteins with ssDNA within the DNA unwinding element (DUE) in the AT-rich region of the plasmid replication origin.

\section{Conclusion}

The relevant information of oriC could be found from the oriC predicting tool such as Ori-Finder as well as the online databases DoriC which include the locations of replication origins sites for thousands of bacterial chromosomes and archaeal genomes. Based on the predicted results, we can identify and confirm the interactions at origins of replication by experimental methods. Of course, purifying replication relevant protein is another pivotal step for the research. An ideal method would require minimal cell numbers or purified protein, could be able to detect rare interactions with high specificity and sensitivity, as well as it could be easily modified to quantify interactions and provide complete information on either of protein or DNA. In vitro techniques provide better quantitative characterization but require isolation of active, soluble protein, which can be challenging and impractical in high-throughput assays. Additionally, protein function may depend strongly on assay conditions; hence, a non-native in vitro environment can give rise to results contradictory to those performed in an in vivo assay. Alternatively, in vivo assays provide a nativelike environment for studying the protein-DNA interaction. Due to the restriction of experimental conditions both in vivo and in vitro, as showed in the review, more than one method were applied in most of experiments to measure the multiple protein-DNA interactions that take place in and around replication origins. And outstanding results were received by them.

However, the sequence of replication origins must be known in methods of EMSA, SPR, ITC, and DNase I footprinting. ChIP and ChIP-seq detect replication origin interactions genome-wide under the condition of unknown or known binding sequences. Through ChIP-seq, the binding sequences could be confirmed precisely. And, the most important point is that we can visually observe the amount change of oriBPS during the cell cycle. Thus the results could help us to understand the mechanisms and regulations of microbial replication initiation clearly. As was showed in the research about how DnaA and essential response regulator CtrA compete to control C. crescentus chromosome replication, previous EMSA experiments was used for single DnaA binding site targets (G1 DnaA box), then DNase I footprinting assay was applied to identify replication origin (Cori) sites (G1, G2, W1, W2, W3, W4, W5) protected by DnaA and the position of CtrA binding site 'e' (Taylor et al., 2011). From the figure of autoradiograph of the sequencing gel, CtrA obscures some DnaA protected sites, and all others DnaA is displaced by CtrA binding. The result of DNase I footprinting assay showed the weaker binding ability of DnaA proteins of C. crescentus than CtrA. The followed ChIP assay in vivo and western blot showed that DnaA is continuously present during the cell cycle, and CtrA proteolysis coincides with DnaA binding to Cori. Therefore, series of assays proved that DnaA is regarded primarily as a chromosome replication regulator and secondarily 
as a transcription regulator, CtrA is regarded primarily as a transcription regulator.

These methods have promoted the development in this field, however, a numerous of problems need to be solved timely. Many techniques were explored to detect the interaction of protein and nucleic acids, while how to improve these techniques to employ in the study of replication origins will be the further work that we do. Hence, we envisage that progress in these technologies will further improve detection abilities and allow sensitive, fast, and cost-effective biochemical analysis both in laboratories and in the field. This development will further extend the potential applications and allow them to be used far more widely. With the development of science and technology and strong cooperation

\section{References}

Abe, Y., Jo, T., Matsuda, Y., Matsunaga, C., Katayama, T., and Ueda, T. (2007). Structure and function of DnaA N-terminal Domains: specific sites and mechanisms in inter-DnaA interaction and in DnaB helicase loading on oriC. J. Biol. Chem. 282, 17816-17827. doi: 10.1074/jbc.M701841200

Alves, C., and Cunha, C. (2012). Electrophoretic mobility shift assay: analyzing protein-nucleic acid interactions. Nat. Protoc. 2, 1849-1861. doi: 10.1038/nprot.2007.249

Arias-Palomo, E., O'shea, V. L., Hood, I. V., and Berger, J. M. (2013). The bacterial DnaC helicase loader is a DnaB ring breaker. Cell 153, 438-448. doi: 10.1016/j.cell.2013.03.006

Aves, S. J. (2009). "DNA replication initiation," in DNA Replication, eds S. Vengrova and J. Z. Dalgaard (New York, NY: Humana Press), 1-16. doi: 10.1093/jexbot/52.355.193

Baird, C. L., and Myszka, D. G. (2001). Current and emerging commercial optical biosensors. J. Mol. Recognit. 14, 261-268. doi: 10.1002/jmr.544

Baker, T. A., and Bell, S. P. (1998). Polymerases and the replisome: machines within machines. Cell 92, 295-305. doi: 10.1016/S0092-8674(00)80923-X

Barry, E. R., and Bell, S. D. (2006). DNA replication in the archaea. Microbiol. Mol. Biol. Rev. 70, 876-887. doi: 10.1128/MMBR.00029-06

Berquist, B. R., and DasSarma, S. (2003). An archaeal chromosomal autonomously replicating sequence element from an extreme halophile, Halobacterium sp. strain NRC-1. J. Bacteriol. 185, 5959-5966. doi: 10.1128/JB.185.20.59595966.2003

Bielinsky, A.-K., and Gerbi, S. A. (1998). Discrete start sites for DNA synthesis in the yeast ARS1 origin. Science 279, 95-98. doi: 10.1126/science.279.5347.95

Blaesing, F., Weigel, C., Welzeck, M., and Messer, W. (2000). Analysis of the DNAbinding domain of Escherichia coli DnaA protein. Mol. Microbiol. 36, 557-569. doi: 10.1046/j.1365-2958.2000.01881.x

Bolduc, O. R., and Masson, J.-F. (2011). Advances in surface plasmon resonance sensing with nanoparticles and thin films: nanomaterials, surface chemistry, and hybrid plasmonic techniques. Anal. Chem. 83, 8057-8062. doi: $10.1021 /$ ac2012976

Boonsongrit, Y., Mueller, B. W., and Mitrevej, A. (2008). Characterization of drug-chitosan interaction by $1 \mathrm{H} \mathrm{NMR,} \mathrm{FTIR} \mathrm{and} \mathrm{isothermal} \mathrm{titration}$ calorimetry. Eur. J. Pharm. Biopharm. 69, 388-395. doi: 10.1016/j.ejpb.2007. 11.008

Buck, M. J., and Lieb, J. D. (2004). ChIP-chip: considerations for the design, analysis, and application of genome-wide chromatin immunoprecipitation experiments. Genomics 83, 349-360. doi: 10.1016/j.ygeno.2003.11.004

Buck, M. J., Nobel, A. B., and Lieb, J. D. (2005). ChIPOTle: a user-friendly tool for the analysis of ChIP-chip data. Genome Biol. 6, R97. doi: 10.1186/gb-2005-6-11r97

Carey, M. F., Peterson, C. L., and Smale, S. T. (2009). Chromatin immunoprecipitation (ChIP). Cold Spring Harb. Protoc. 2009, db-rot5279. doi: $10.1101 /$ pdb.prot5279

Carey, M. F., Peterson, C. L., and Smale, S. T. (2012). Experimental strategies for the identification of DNA-binding proteins. Cold Spring Harb. Protoc. 2012, db. to067470. doi: $10.1101 /$ pdb.top 067470 between the various disciplines, research strategy with innovative thinking and novel methods will continue to emerge. It can be predicted that research on the regulation and mechanism of replication origins will make considerable progress in the near further.

\section{Acknowledgments}

The present work was partially supported by National High Technology Research and Development Program of China (Grant No. 2015AA020701) and National Natural Science Foundation of China (Grant No. 31470967).

Carey, M. F., Peterson, C. L., and Smale, S. T. (2013a). DNase I footprinting. Cold Spring Harb. Protoc. 2013, db. rot074328. doi: 10.1101/pdb.prot074328

Carey, M. F., Peterson, C. L., and Smale, S. T. (2013b). Electrophoretic mobility shift assays. Cold Spring Harb. Protoc. 2013, db. rot075861. doi: 10.1101/pdb.prot075861

Caspi, R., Helinski, D. R., Pacek, M., and Konieczny, I. (2000). Interactions of DnaA proteins from distantly related bacteria with the replication origin of the broad host range plasmid RK2. J. Biol. Chem. 275, 18454-18461. doi: 10.1074/jbc.M000552200

Chen, H., and Chang, G. D. (2001). Simultaneous immunoblotting analysis with activity gel electrophoresis in a single polyacrylamide gel. Electrophoresis 22, 1894-1899. doi: 10.1007/978-1-59745-542-8_4

Chumsakul, O., Nakamura, K., Kurata, T., Sakamoto, T., Hobman, J. L., Ogasawara, N., et al. (2013). High-resolution mapping of in vivo genomic transcription factor binding sites using in situ DNase I footprinting and ChIPseq. DNA Res. 20, 325-338. doi: 10.1093/dnares/dst013

Clegg, R. M. (1995). Fluorescence resonance energy transfer. Curr. Opin. Biotechnol. 6, 103-110. doi: 10.1016/0958-1669(95)80016-6

Coker, J. A., Dassarma, P., Capes, M., Wallace, T., Mcgarrity, K., Gessler, R., et al. (2009). Multiple replication origins of Halobacterium sp. strain NRC-1: properties of the conserved orc7-dependent oriC1. J. Bacteriol. 191, 5253-5261. doi: 10.1128/JB.00210-09

Contursi, P., Pisani, F. M., Grigoriev, A., Cannio, R., Bartolucci, S., and Rossi, M. (2004). Identification and autonomous replication capability of a chromosomal replication origin from the archaeon Sulfolobus solfataricus. Extremophiles 8, 385-391. doi: 10.1007/s00792-004-0399-y

Cooper, M. A. (2002). Optical biosensors in drug discovery. Nat. Rev. Drug Discov. 1, 515-528. doi: 10.1038/nrd838

Crane-Robinson, C., Dragan, A. I., and Read, C. M. (2009). "Defining the thermodynamics of protein/DNA complexes and their components using micro-calorimetry," in DNA-Protein Interactions, Vol. 543, eds B. Leblanc and T. Moss (New York, NY: Humana Press), 625-651. doi: 10.1007/978-1-60327015-1_37

Dame, R. T., Kalmykowa, O. J., and Grainger, D. C. (2011). Chromosomal macrodomains and associated proteins: implications for DNA organization and replication in gram negative bacteria. PLoS Genet. 7:e1002123. doi: 10.1371/journal.pgen.1002123

Despeyroux, D., Walker, N., Pearce, M., Fisher, M., Mcdonnell, M., Bailey, S., et al. (2000). Characterization of ricin heterogeneity by electrospray mass spectrometry, capillary electrophoresis, and resonant mirror. Anal. Biochem. 279, 23-36. doi: 10.1006/abio.1999.4423

Dey, B., Thukral, S., Krishnan, S., Chakrobarty, M., Gupta, S., Manghani, C., et al. (2012). DNA-protein interactions: methods for detection and analysis. Mol. Cell. Biochem. 365, 279-299. doi: 10.1007/s11010-0121269-z

Di Paola, D., Rampakakis, E., Chan, M. K., Arvanitis, D. N., and ZannisHadjopoulos, M. (2010). Increased origin activity in transformed versus normal cells: identification of novel protein players involved in DNA replication and cellular transformation. Nucleic Acids Res. 38, 2314-2331. doi: $10.1093 /$ nar/gkp1192 
Donczew, R., Weigel, C., Lurz, R., Zakrzewska-Czerwińska, J., and ZawilakPawlik, A. (2012). Helicobacter pylori oriC-the first bipartite origin of chromosome replication in Gram-negative bacteria. Nucleic Acids Res. 40, 9647-9660. doi: 10.1093/nar/gks742

Duggin, I. G., Dubarry, N., and Bell, S. D. (2011). Replication termination and chromosome dimer resolution in the archaeon Sulfolobus solfataricus. EMBO J. 30, 145-153. doi: 10.1038/emboj.2010.301

Duggin, I. G., Mccallum, S. A., and Bell, S. D. (2008). Chromosome replication dynamics in the archaeon Sulfolobus acidocaldarius. Proc. Natl. Acad. Sci. U.S.A. 105, 16737-16742. doi: 10.1073/pnas.0806414105

Eaton, M. L., Galani, K., Kang, S., Bell, S. P., and MacAlpine, D. M. (2010). Conserved nucleosome positioning defines replication origins. Genes Dev. 24, 748-753. doi: 10.1101/gad.1913210

Eaton, M. L., Prinz, J. A., MacAlpine, H. K., Tretyakov, G., Kharchenko, P. V., and MacAlpine, D. M. (2011). Chromatin signatures of the Drosophila replication program. Genome Res. 21, 164-174. doi: 10.1101/gr.116038.110

Falconer, R. J., and Collins, B. M. (2011). Survey of the year 2009: applications of isothermal titration calorimetry. J. Mol. Recognit. 24, 1-16. doi: 10.1002/jmr.1073

Falconer, R. J., Penkova, A., Jelesarov, I., and Collins, B. M. (2010). Survey of the year 2008: applications of isothermal titration calorimetry. J. Mol. Recognit. 23, 395-413. doi: 10.1002/jmr.1025

Felczak, M. M., and Kaguni, J. M. (2004). The box VII motif of Escherichia coli DnaA protein is required for DnaA oligomerization at the $E$. coli replication origin. J. Biol. Chem. 279, 51156-51162. doi: 10.1074/jbc.M4096 95200

Fourtounis, J., Falgueyret, J.-P., and Sayegh, C. E. (2011). Assessing protein-RNA interactions using microfluidic capillary mobility shift assays. Anal. Biochem. 411, 161-163. doi: 10.1016/j.ab.2010.11.042

Fox, K. R., and Waring, M. J. (1987). The use of micrococcal nuclease as a probe for drug-binding sites on DNA. Biochim. Biophys. Acta 909, 145-155. doi: 10.1016/0167-4781(87)90036-4

Freyer, M. W., and Lewis, E. A. (2008). Isothermal titration calorimetry: experimental design, data analysis, and probing macromolecule/ligand binding and kinetic interactions. Methods Cell Biol. 84, 79-113. doi: 10.1016/S0091679X(07)84004-0

Fried, M. G. (1989). Measurement of protein-DNA interaction parameters by electrophoresis mobility shift assay. Electrophoresis 10, 366-376. doi: 10.1002/elps.1150100515

Fujikawa, N., Kurumizaka, H., Nureki, O., Terada, T., Shirouzu, M., Katayama, T., et al. (2003). Structural basis of replication origin recognition by the DnaA protein. Nucleic Acids Res. 31, 2077-2086. doi: 10.1093/nar/gkg309

Fujita, T., Asano, Y., Ohtsuka, J., Takada, Y., Saito, K., Ohki, R., et al. (2013). Identification of telomere-associated molecules by engineered DNA-binding molecule-mediated chromatin immunoprecipitation (enChIP). Sci. Rep. 3:3171. doi: 10.1038/srep03171

Fuller, R. S., Funnell, B. E., and Kornberg, A. (1984). The dnaA protein complex with the E. coli chromosomal replication origin (oriC) and other DNA sites. Cell 38, 889-900. doi: 10.1016/0092-8674(84)90284-8

Gao, F. (2014). Recent advances in the identification of replication origins based on the Z-curve method. Curr. Genomics 15, 104-112. doi: $10.2174 / 1389202915999140328162938$

Gao, F., Luo, H., and Zhang, C.-T. (2012). DeOri: a database of eukaryotic DNA replication origins. Bioinformatics 28, 1551-1552. doi: 10.1093/bioinformatics/bts151

Gao, F., Luo, H., and Zhang, C.-T. (2013). DoriC 5.0: an updated database of oriC regions in both bacterial and archaeal genomes. Nucleic Acids Res. 41, D90-D93. doi: $10.1093 /$ nar/gks 990

Gao, F., and Zhang, C.-T. (2007). DoriC: a database of oriC regions in bacterial genomes. Bioinformatics 23, 1866-1867. doi: 10.1093/bioinformatics/btm255

Gao, F., and Zhang, C.-T. (2008). Ori-Finder: a web-based system for finding oriCs in unannotated bacterial genomes. BMC Bioinformatics 9:79. doi: 10.1186/14712105-9-79

Garg, P., and Burgers, P. M. (2005). DNA polymerases that propagate the eukaryotic DNA replication fork. Crit. Rev. Biochem. Mol. Biol. 40, 115-128. doi: 10.1080/10409230590935433

Gerbi, S. A., and Bielinsky, A.-K. (1997). Replication initiation point mapping. Methods 13, 271-280. doi: 10.1006/meth.1997.0526
Gilbert, D. M. (2010). Evaluating genome-scale approaches to eukaryotic DNA replication. Nat. Rev. Genet. 11, 673-684. doi: 10.1038/nrg2830

Gilbert, S. D., and Batey, R. T. (2009). "Monitoring RNA-ligand interactions using isothermal titration calorimetry," in Riboswitches, ed. A. Serganov (New York, NY: Humana Press), 97-114. doi: 10.1007/978-1-59745-558-9_8

Gorbatyuk, B., and Marczynski, G. T. (2005). Regulated degradation of chromosome replication proteins DnaA and CtrA in Caulobacter crescentus. Mol. Microbiol. 55, 1233-1245. doi: 10.1111/j.1365-2958.2004.04459.x

Granger-Schnarr, M., Lloubes, R., De Murcia, G., and Schnarr, M. (1988). Specific protein-DNA complexes: immunodetection of the protein component after gel electrophoresis and Western blotting. Anal. Biochem. 174, 235-238. doi: 10.1016/0003-2697(88)90540-4

Hellman, L. M., and Fried, M. G. (2007). Electrophoretic mobility shift assay (EMSA) for detecting protein-nucleic acid interactions. Nat. Protoc. 2, 18491861. doi: $10.1038 /$ nprot.2007.249

Hoa, X., Kirk, A., and Tabrizian, M. (2007). Towards integrated and sensitive surface plasmon resonance biosensors: a review of recent progress. Biosens. Bioelectron. 23, 151-160. doi: 10.1016/j.bios.2007.07.001

Homola, J., Yee, S. S., and Gauglitz, G. (1999). Surface plasmon resonance sensors: review. Sens. Actuators B Chem. 54, 3-15. doi: 10.1016/S0925-4005(98) 00321-9

Horak, C. E., and Snyder, M. (2002). ChIP-chip: a genomic approach for identifying transcription factor binding sites. Methods Enzymol. 350, 469-483. doi: 10.1016/S0076-6879(02)50979-4

Hoshino, A., and Fujii, H. (2009). Insertional chromatin immunoprecipitation: a method for isolating specific genomic regions. J. Biosci. Bioeng. 108, 446-449. doi: 10.1016/j.jbiosc.2009.05.005

Hou, W., and Cronin, S. B. (2013). A review of surface plasmon resonanceenhanced photocatalysis. Adv. Funct. Mater. 23, 1612-1619. doi: 10.1002/adfm. 201202148

Huberman, J. A. (1999). Genetic methods for characterizing the cis-acting components of yeast dna replication origins. Methods 18, 356-367. doi: 10.1006/meth.1999.0792

Huebert, D. J., Kamal, M., O'donovan, A., and Bernstein, B. E. (2006). Genomewide analysis of histone modifications by ChIP-on-chip. Methods 40, 365-369. doi: 10.1016/j.ymeth.2006.07.032

Inoue, S., Kaji, N., Kataoka, M., Shinohara, Y., Okamoto, Y., Tokeshi, M., et al. (2011). Rapid qualitative evaluation of DNA transcription factor NF$\kappa \mathrm{B}$ by microchip electrophoretic mobility shift assay in mammalian cells. Electrophoresis 32, 3241-3247. doi: 10.1002/elps.201100261

Jacob, F., Brenner, S., and Cuzin, F. (1963). On the Regulation of DNA Replication in Bacteria. Cold Spring Harbor Symposia on Quantitative Biology, Vol. 28. New York, NY: Cold Spring Harbor Laboratory Press, 329-348.

Jiang, Y., Pacek, M., Helinski, D. R., Konieczny, I., and Toukdarian, A. (2003). A multifunctional plasmid-encoded replication initiation protein both recruits and positions an active helicase at the replication origin. Proc. Natl. Acad. Sci. U.S.A. 100, 8692-8697. doi: 10.1073/pnas.1532393100

Jing, D., Agnew, J., Patton, W. F., Hendrickson, J., and Beechem, J. M. (2003). A sensitive two-color electrophoretic mobility shift assay for detecting both nucleic acids and protein in gels. Proteomics 3, 1172-1180. doi: 10.1002/pmic. 200300438

Johnson, A., and O'Donnell, M. (2005). Cellular DNA replicases: components and dynamics at the replication fork. Annu. Rev. Biochem. 74, 283-315. doi: 10.1146/annurev.biochem.74.011303.073859

Johnson, D. S., Mortazavi, A., Myers, R. M., and Wold, B. (2007). Genome-wide mapping of in vivo protein-DNA interactions. Science 316, 1497-1502. doi: 10.1126/science.1141319

Karns, K., Vogan, J. M., Qin, Q., Hickey, S. F., Wilson, S. C., Hammond, M. C., et al. (2013). Microfluidic screening of electrophoretic mobility shifts elucidates riboswitch binding function. J. Am. Chem. Soc. 135, 3136-3143. doi: 10.1021/ja310742m

Katarzyna, W., Eugenia, F.-P. M., Katarzyna, B., Magdalena, R., Fernando, M.-H., and Igor, K. (2014). Sequence-specific interactions of Rep proteins with ssDNA in the AT-rich region of the plasmid replication origin. Nucleic Acids Res. 42, gku453. doi: 10.1093/nar/gku453

Katayama, T. (2008). Roles for the AAA + motifs of DnaA in the initiation of DNA replication. Biochem. Soc. Trans. 36(Pt 1), 78-82. doi: 10.1042/BST03 60078 
Kawakami, H., and Katayama, T. (2010). DnaA, ORC, and Cdc6: similarity beyond the domains of life and diversity. Biochem. Cell Biol. 88, 49-62. doi: 10.1139/o09-154

Kelman, Z., and O’Donnell, M. (1995). DNA polymerase III holoenzyme: structure and function of a chromosomal replicating machine. Annu. Rev. Biochem. 64, 171-200. doi: 10.1146/annurev.bi.64.070195.001131

Keyamura, K., Fujikawa, N., Ishida, T., Ozaki, S., Su'etsugu, M., Fujimitsu, K., et al. (2007). The interaction of DiaA and DnaA regulates the replication cycle in E. coli by directly promoting ATP DnaA-specific initiation complexes. Genes Dev. 21, 2083-2099. doi: 10.1101/gad.1561207

Khan, S. H., Farkas, K., Kumar, R., and Ling, J. (2012). A versatile method to measure the binding to basic proteins by surface plasmon resonance. Anal. Biochem. 421, 385-390. doi: 10.1016/j.ab.2011.12.006

Khodursky, A. B., Peter, B. J., Schmid, M. B., Derisi, J., Botstein, D., Brown, P. O., et al. (2000). Analysis of topoisomerase function in bacterial replication fork movement: use of DNA microarrays. Proc. Natl. Acad. Sci. U.S.A. 97, 9419-9424. doi: 10.1073/pnas.97.17.9419

Kim, J.-M., To, T. K., Tanaka, M., Endo, T. A., Matsui, A., Ishida, J., et al. (2014). "Highly reproducible ChIP-on-chip analysis to identify genome-wide protein binding and chromatin status in Arabidopsis thaliana," in Arabidopsis Protocols, eds J. J. Sanchez-Serrano and J. Salinas (Berlin: Springer), 405-426. doi: 10.1007/978-1-62703-580-4_22

Kitagawa, R., Mitsuki, H., Okazaki, T., and Ogawa, T. (1996). A novel DnaA protein-binding site at $94.7 \mathrm{~min}$ on the Escherichia coli chromosome. Mol. Microbiol. 19, 1137-1147. doi: 10.1046/j.1365-2958.1996.453983.x

Komori, K., and Ishino, Y. (2001). Replication protein A in Pyrococcus furiosus is involved in homologous DNA recombination. J. Biol. Chem. 276, 25654-25660. doi: 10.1074/jbc.M102423200

Kozlov, A. G., and Lohman, T. M. (2012). "SSB binding to ssDNA using isothermal titration calorimetry," in Single-Stranded DNA Binding Proteins, ed. J. L. Keck (New York, NY: Springer), 37-54. doi: 10.1007/978-1-62703-0 32-8_3

Ladd, J., Lu, H., Taylor, A. D., Goodell, V., Disis, M. L., and Jiang, S. (2009). Direct detection of carcinoembryonic antigen autoantibodies in clinical human serum samples using a surface plasmon resonance sensor. Colloids Surf. B Biointerfaces 70, 1-6. doi: 10.1016/j.colsurfb.2008.11.032

Landt, S. G., Marinov, G. K., Kundaje, A., Kheradpour, P., Pauli, F., Batzoglou, S., et al. (2012). ChIP-seq guidelines and practices of the ENCODE and modENCODE consortia. Genome Res. 22, 1813-1831. doi: 10.1101/gr.136184.111

Lane, D., Prentki, P., and Chandler, M. (1992). Use of gel retardation to analyze protein-nucleic acid interactions. Microbiol. Rev. 56, 509-528.

Leblanc, B., and Moss, T. (2001). "DNase I footprinting," in DNA-Protein Interactions, ed. T. Moss (New York, NY: Humana Press), 31-38. doi: 10.1385/1-59259-208-2:031

Lee, H., and Romero, J. (2012). Origin of DNA replication at the human lamin B2 locus: OBR or ABR? Cell Cycle 11, 4281-4283. doi: 10.4161/cc. 21992

Liedberg, B., Nylander, C., and Lundström, I. (1995). Biosensing with surface plasmon resonance-how it all started. Biosens. Bioelectron. 10, i-ix. doi: 10.1016/0956-5663(95)96965-2

Liu, J., Pei, H., Mei, S., Li, J., Zhou, L., and Xiang, H. (2008). Replication initiator DnaA interacts with an anti-terminator NusG in T. tengcongensis. Biochem. Biophys. Commun. 371, 573-577. doi: 10.1016/j.bbrc.2008.04.131

Liu, Y., Dong, Y., Jauw, J., Linman, M. J., and Cheng, Q. (2010). Highly sensitive detection of protein toxins by surface plasmon resonance with biotinylationbased inline atom transfer radical polymerization amplification. Anal. Chem. 82, 3679-3685. doi: 10.1021/ac1000114

Lundgren, M., Andersson, A., Chen, L., Nilsson, P., and Bernander, R. (2004). Three replication origins in Sulfolobus species: synchronous initiation of chromosome replication and asynchronous termination. Proc. Natl. Acad. Sci. U.S.A. 101, 7046-7051. doi: 10.1073/pnas.0400656101

Luo, H., Zhang, C.-T., and Gao, F. (2014). Ori-Finder 2, an integrated tool to predict replication origins in the archaeal genomes. Front. Microbiol. 5:482. doi: 10.3389/fmicb.2014.00482

Lyon, L. A., Musick, M. D., and Natan, M. J. (1998). Colloidal Au-enhanced surface plasmon resonance immunosensing. Anal. Chem. 70, 5177-5183. doi: $10.1021 /$ ac9809940
Maisnier-Patin, S., Malandrin, L., Birkeland, N. K., and Bernander, R. (2002). Chromosome replication patterns in the hyperthermophilic euryarchaea Archaeoglobus fulgidus and Methanocaldococcus (Methanococcus) jannaschii. Mol. Microbiol. 45, 1443-1450. doi: 10.1046/j.1365-2958.2002.03111.x

Malott, M., and Leffak, M. (1999). Activity of the c-myc replicator at an ectopic chromosomal location. Mol. Cell. Biol. 19, 5685-5695.

Marinsek, N., Barry, E. R., Makarova, K. S., Dionne, I., Koonin, E. V., and Bell, S. D. (2006). GINS, a central nexus in the archaeal DNA replication fork. EMBO Rep. 7, 539-545. doi: 10.1038/sj.embor.7400649

Martin, M. M., Ryan, M., Kim, R., Zakas, A. L., Fu, H., Lin, C. M., et al. (2011). Genome-wide depletion of replication initiation events in highly transcribed regions. Genome Res. 21, 1822-1832. doi: 10.1101/gr.124644.111

Martinez, J. C., Murciano-Calles, J., Cobos, E. S., Iglesias-Bexiga, M., Luque, I., and Ruiz-Sanz, J. (2013). "Isothermal titration calorimetry: thermodynamic analysis of the binding thermograms of molecular recognition events by using equilibrium models," in Applications of Calorimetry in a Wide Context - Differential Scanning Calorimetry, Isothermal Titration Calorimetry and Microcalorimetry, Chap. 4, ed. A. A. Elkordy (Rijeka: INTECH). doi: 10.5772/53311

Matsunaga, F., Forterre, P., Ishino, Y., and Myllykallio, H. (2001). In vivo interactions of archaeal $\mathrm{Cdc6} / \mathrm{Orcl}$ and minichromosome maintenance proteins with the replication origin. Proc. Natl. Acad. Sci. U.S.A. 98, 11152 11157. doi: 10.1073/pnas.191387498

Matsunaga, F., Glatigny, A., Mucchielli-Giorgi, M.-H., Agier, N., Delacroix, H., Marisa, L., et al. (2007). Genomewide and biochemical analyses of DNAbinding activity of Cdc6/Orc1 and $\mathrm{Mcm}$ proteins in Pyrococcus sp. Nucleic Acids Res. 35, 3214-3222. doi: 10.1093/nar/gkm212

Matsunaga, F., Norais, C., Forterre, P., and Myllykallio, H. (2003). Identification of short 'eukaryotic' Okazaki fragments synthesized from a prokaryotic replication origin. EMBO Rep. 4, 154-158. doi: 10.1038/sj.embor.embor732

Matulis, D., Rouzina, I., and Bloomfield, V. A. (2000). Thermodynamics of DNA binding and condensation: isothermal titration calorimetry and electrostatic mechanism. J. Mol. Biol. 296, 1053-1063. doi: 10.1006/jmbi.1999.3470

Memelink, J. (2013). "Electrophoretic mobility shift assay for the analysis of interactions of jasmonic acid-responsive transcription factors with dna," in Jasmonate Signaling, eds A. Goossens and L. Pauwels (Berlin: Springer), 209225. doi: 10.1007/978-1-62703-414-2_17

Messer, W. (2002). The bacterial replication initiator DnaA. DnaA and oriC, the bacterial mode to initiate DNA replication. FEMS Microbiol. Rev. 26, 355-374. doi: 10.1111/j.1574-6976.2002.tb00620.x

Messer, W., Blaesing, F., Jakimowicz, D., Krause, M., Majka, J., Nardmann, J., et al. (2001). Bacterial replication initiator DnaA. Rules for DnaA binding and roles of DnaA in origin unwinding and helicase loading. Biochimie 83, 5-12. doi: 10.1016/S0300-9084(00)01216-5

Michalet, X., Pinaud, F. F., Bentolila, L. A., Tsay, J. M., Doose, S., Li, J. J., et al. (2005). Quantum dots for live cells, in vivo imaging, and diagnostics. Science 307, 538-544. doi: 10.1126/science. 1104274

Michel, B., and Bernander, R. (2014). Chromosome replication origins: do we really need them? Bioessays 36, 585-590. doi: 10.1002/bies.201400003

Morozova, O., and Marra, M. A. (2008). Applications of next-generation sequencing technologies in functional genomics. Genomics 92, 255-264. doi: 10.1016/j.ygeno.2008.07.001

Murphy, M. B., Fuller, S. T., Richardson, P. M., and Doyle, S. A. (2003). An improved method for the in vitro evolution of aptamers and applications in protein detection and purification. Nucleic Acids Res. 31, e110-e110. doi: 10.1093/nar/gng110

Myllykallio, H., Lopez, P., López-García, P., Heilig, R., Saurin, W., Zivanovic, Y., et al. (2000). Bacterial mode of replication with eukaryoticlike machinery in a hyperthermophilic archaeon. Science 288, 2212-2215. doi: 10.1126/science.288.5474.2212

Nawotka, K. A., and Huberman, J. A. (1988). Two-dimensional gel electrophoretic method for mapping DNA replicons. Mol. Cell. Biol. 8, 1408-1413. doi: 10.1128/MCB.8.4.1408

Newlon, C. S. (1996). DNA Replication in Eukaryotic Cells. Plainview, NY: Cold Spring Harbor Laboratory Press, 873-914.

Newman, G., and Crooke, E. (2000). DnaA, the initiator of Escherichia coli chromosomal replication, is located at the cell membrane. J. Bacteriol. 182, 2604-2610. doi: 10.1128/JB.182.9.2604-2610.2000 
Norais, C., Hawkins, M., Hartman, A. L., Eisen, J. A., Myllykallio, H., and Allers, T. (2007). Genetic and physical mapping of DNA replication origins in Haloferax volcanii. PLoS Genet. 3:e77. doi: 10.1371/journal.pgen.0030077

Nozaki, S., and Ogawa, T. (2008). Determination of the minimum domain II size of Escherichia coli DnaA protein essential for cell viability. Microbiology 154(Pt 11), 3379-3384. doi: 10.1099/mic.0.2008/019745-0

O’Donnell, M., Langston, L., and Stillman, B. (2013). Principles and concepts of DNA replication in bacteria, archaea, and eukarya. Cold Spring Harb. Perspect. Biol. 5:a010108. doi: 10.1101/cshperspect.a010108

Ogura, Y., Imai, Y., Ogasawara, N., and Moriya, S. (2001). Autoregulation of the dnaA-dnaN operon and effects of DnaA protein levels on replication initiation in Bacillus subtilis. J. Bacteriol. 183, 3833-3841. doi: 10.1128/JB.183.13.38333841.2001

Orlando, V. (2000). Mapping chromosomal proteins in vivo by formaldehydecrosslinked-chromatin immunoprecipitation. Trends Biochem. Sci. 25, 99-104. doi: 10.1016/S0968-0004(99)01535-2

Ozaki, S., and Katayama, T. (2009). DnaA structure, function, and dynamics in the initiation at the chromosomal origin. Plasmid 62, 71-82. doi: 10.1016/j.plasmid.2009.06.003

Ozaki, S., and Katayama, T. (2012). Highly organized DnaA-oriC complexes recruit the single-stranded DNA for replication initiation. Nucleic Acids Res. 40, 1648-1665. doi: 10.1093/nar/gkr832

Ozaki, S., Kawakami, H., Nakamura, K., Fujikawa, N., Kagawa, W., Park, S. Y., et al. (2008). A common mechanism for the ATP-DnaA-dependent formation of open complexes at the replication origin. J. Biol. Chem. 283, 8351-8362. doi: 10.1074/jbc.M708684200

Pan, Y., Karns, K., and Herr, A. E. (2014). Microfluidic electrophoretic mobility shift assays for quantitative biochemical analysis. Electrophoresis 35, 2078-2090. doi: 10.1002/elps.201300500

Parab, H. J., Jung, C., Lee, J.-H., and Park, H. G. (2010). A gold nanorod-based optical DNA biosensor for the diagnosis of pathogens. Biosens. Bioelectron. 26, 667-673. doi: 10.1016/j.bios.2010.06.067

Pattnaik, P. (2005). Surface plasmon resonance. Appl. Biochem. Biotechnol. 126, 79-92. doi: 10.1385/ABAB:126:2:079

Pei, H., Liu, J., Li, J., Guo, A., Zhou, J., and Xiang, H. (2007). Mechanism for the $\mathrm{TtDnaA}-\mathrm{Tt}$-oriC cooperative interaction at high temperature and duplex opening at an unusual AT-rich region in Thermoanaerobacter tengcongensis. Nucleic Acids Res. 35, 3087-3099. doi: 10.1093/nar/gkm137

Pelve, E. A., Lindås, A. C., Knöppel, A., Mira, A., and Bernander, R. (2012). Four chromosome replication origins in the archaeon Pyrobaculum calidifontis. Mol. Microbiol. 85, 986-995. doi: 10.1111/j.1365-2958.2012.08155.x

Pelve, E. A., Martens-Habbena, W., Stahl, D. A., and Bernander, R. (2013). Mapping of active replication origins in vivo in thaum- and euryarchaeal replicons. Mol. Microbiol. 90, 538-550. doi: 10.1111/mmi.12382

Pernites, R. B., Ponnapati, R. R., and Advincula, R. C. (2010). Surface plasmon resonance (SPR) detection of theophylline via electropolymerized molecularly imprinted polythiophenes. Macromolecules 43, 9724-9735. doi: $10.1021 / \mathrm{ma101868y}$

Pierce, M. M., Raman, C., and Nall, B. T. (1999). Isothermal titration calorimetry of protein-protein interactions. Methods 19, 213-221. doi: 10.1006/meth.1999.0852

Raghuraman, M., Winzeler, E. A., Collingwood, D., Hunt, S., Wodicka, L., Conway, A., et al. (2001). Replication dynamics of the yeast genome. Science 294, 115-121. doi: 10.1126/science.294.5540.115

Richter, S., and Messer, W. (1995). Genetic structure of the dnaA region of the cyanobacterium Synechocystis sp. strain PCC6803. J. Bacteriol. 177, 4245-4251.

Riddick, L., and Brumley, W. C. (2008). "Capillary electrophoresis with laserinduced fluorescence," in Capillary Electrophoresis, ed. P. Schmitt-Kopplin (New York, NY: Humana Press), 119-134. doi: 10.1007/978-1-59745-376-9_6

Robertson, G., Hirst, M., Bainbridge, M., Bilenky, M., Zhao, Y., Zeng, T., et al. (2007). Genome-wide profiles of STAT1 DNA association using chromatin immunoprecipitation and massively parallel sequencing. Nat. Methods 4, 651657. doi: $10.1038 /$ nmeth 1068

Robinson, N. P., and Bell, S. D. (2007). Extrachromosomal element capture and the evolution of multiple replication origins in archaeal chromosomes. Proc. Natl. Acad. Sci. U.S.A. 104, 5806-5811. doi: 10.1073/pnas.0700206104

Robinson, N. P., Dionne, I., Lundgren, M., Marsh, V. L., Bernander, R., and Bell, S. D. (2004). Identification of two origins of replication in the single chromosome of the archaeon Sulfolobus solfataricus. Cell 116, 25-38. doi: 10.1016/S0092-8674(03)01034-1

Roth, A., and Messer, W. (1995). The DNA binding domain of the initiator protein DnaA. EMBO J. 14, 2106-2111.

Roth, A., and Messer, W. (1998). High-affinity binding sites for the initiator protein DnaA on the chromosome of Escherichia coli. Mol. Microbiol. 28, 395-401. doi: 10.1046/j.1365-2958.1998.00813.x

Sahai, N. (2011). Surface plasmon resonance. Encycl. Astrobiol. 1642-1642. doi: 10.1007/978-3-642-11274-4_1551

Sawhney, S., and Singh, R. (2000). Introductory Practical Biochemistry. Oxford: Alpha Science International Limited.

Schaper, S., Nardmann, J., Lüder, G., Lurz, R., Speck, C., and Messer, W. (2000). Identification of the chromosomal replication origin from Thermus thermophilus and its interaction with the replication initiator DnaA. J. Mol. Biol. 299, 655-665. doi: 10.1006/jmbi.2000.3764

Schmidt, D., Wilson, M. D., Spyrou, C., Brown, G. D., Hadfield, J., and Odom, D. T. (2009). ChIP-seq: using high-throughput sequencing to discover protein-DNA interactions. Methods 48, 240-248. doi: 10.1016/j.ymeth.2009.03.001

Sekimizu, K., Yung, B. Y.-M., and Kornberg, A. (1988). The dnaA protein of Escherichia coli. Abundance, improved purification, and membrane binding. J. Biol. Chem. 263, 7136-7140.

Shah, A. (2009). Chromatin immunoprecipitation sequencing (ChIP-Seq) on the $\mathrm{SOLiD}^{\mathrm{TN}}$ system. Nat. Methods 6.

Shahravan, S. H., Li, I. T., Truong, K., and Shin, J. A. (2011). FRep: a fluorescent protein-based bioprobe for in vivo detection of protein-dna interactions. Anal. Chem. 83, 9643-9650. doi: 10.1021/ac2024602

Sigurskjold, B. W. (2000). Exact analysis of competition ligand binding by displacement isothermal titration calorimetry. Anal. Biochem. 277, 260-266. doi: 10.1006/abio.1999.4402

Singh, M., Holzinger, M., Tabrizian, M., Winters, S., Berner, N. C., Cosnier, S., et al. (2015). Non-covalently functionalized monolayer graphene for sensitivity enhancement of surface plasmon resonance immunosensors. J. Am. Chem. Soc. 137, 2800-2803. doi: 10.1021/ja511512m

Skarstad, K., and Katayama, T. (2013). Regulating DNA replication in bacteria. Cold Spring Harb. Perspect. Biol. 5:a012922. doi: 10.1101/cshperspect.a012922

Smith, A. J., and Humphries, S. E. (2009). Characterization of DNA-binding proteins using multiplexed competitor EMSA. J. Mol. Biol. 385, 714-717. doi: 10.1016/j.jmb.2008.11.035

Speck, C., and Messer, W. (2001). Mechanism of origin unwinding: sequential binding of DnaA to double- and single-stranded DNA. EMBO J. 20, 1469-1476. doi: 10.1093/emboj/20.6.1469

Stead, J. A., Keen, J. N., and Mcdowall, K. J. (2006). The identification of nucleic acid-interacting proteins using a simple proteomics-based approach that directly incorporates the electrophoretic mobility shift assay. Mol. Cell. Proteom. 5, 1697-1702. doi: 10.1074/mcp.T600027-MCP200

Struhl, K., Stinchcomb, D. T., Scherer, S., and Davis, R. W. (1979). High-frequency transformation of yeast: autonomous replication of hybrid DNA molecules. Proc. Natl. Acad. Sci. U.S.A. 76, 1035-1039. doi: 10.1073/pnas.76.3.1035

Sun, C., Zhou, M., Li, Y., and Xiang, H. (2006). Molecular characterization of the minimal replicon and the unidirectional theta replication of pSCM201 in extremely halophilic archaea. J. Bacteriol. 188, 8136-8144. doi: 10.1128/JB.00988-06

Sutton, M. D., and Kaguni, J. M. (1997). Novel alleles of the Escherichia coli dnaA gene. J. Mol. Biol. 271, 693-703. doi: 10.1006/jmbi.1997.1209

Špringer, T. S., Ermini, M. L., ŠPačKová, B., JabloňKů, J., and Homola, J. (2014). Enhancing sensitivity of surface plasmon resonance biosensors by functionalized gold nanoparticles: size matters. Anal. Chem. 86, 10350-10356. doi: $10.1021 /$ ac502637u

Tao, L., Dong, Z., Leffak, M., Zannis-Hadjopoulos, M., and Price, G. (2000). Major DNA replication initiation sites in the c-myc locus in human cells. J. Cell. Biochem. 78, 442-457. doi: 10.1002/1097-4644(20000901)78:3<442::AIDJCB9 > 3.0.CO;2-1

Taylor, J. A., Ouimet, M. C., Wargachuk, R., and Marczynski, G. T. (2011). The Caulobacter crescentus chromosome replication origin evolved two classes of weak DnaA binding sites. Mol. Microbiol. 82, 312-326. doi: 10.1111/j.13652958.2011.07785.x

Testa, A., Donati, G., Yan, P., Romani, F., Huang, T. H.-M., Viganò, M. A., et al. (2005). Chromatin immunoprecipitation (ChIP) on chip experiments 
uncover a widespread distribution of NF-Y binding CCAAT sites outside of core promoters. J. Biol. Chem. 280, 13606-13615. doi: 10.1074/jbc.M414039200

Truax, A. D., and Greer, S. F. (2012). "ChIP and Re-ChIP assays: investigating interactions between regulatory proteins, histone modifications, and the DNA sequences to which they bind," in Transcriptional Regulation, ed. A. Vancura (New York, NY: Springer), 175-188. doi: 10.1007/978-1-61779-376-9_12

Tsai, C., Smider, V., Hwang, B. J., and Chu, G. (2012). "Electrophoretic mobility shift assays for protein-DNA complexes involved in DNA repair," in DNA Repair Protocols, ed. L. Bjergbæk (New York, NY: Humana Press), 53-78. doi: 10.1007/978-1-61779-998-3_5

Van Dyke, M. W., and Dervan, P. B. (1983). Methidiumpropyl-EDTA-Fe (II) and DNase I footprinting report different small molecule binding site sizes on DNA. Nucleic Acids Res. 11, 5555-5567. doi: 10.1093/nar/11.16.5555

Velazquez-Campoy, A., and Freire, E. (2006). Isothermal titration calorimetry to determine association constants for high-affinity ligands. Nat. Protoc. 1, 186-191. doi: 10.1038/nprot.2006.28

Velazquez-Campoy, A., Leavitt, S. A., and Freire, E. (2004). “Characterization of protein-protein interactions by isothermal titration calorimetry," in ProteinProtein Interactions, ed. H. Fu (New York, NY: Humana Press), 35-54. doi: 10.1385/1-59259-762-9:035

Vernis, L., Chasles, M., Pasero, P., Lepingle, A., Gaillardin, C., and Fournier, P. (1999). Short DNA fragments without sequence similarity are initiation sites for replication in the chromosome of the yeast Yarrowia lipolytica. Mol. Biol. Cell 10, 757-769. doi: 10.1091/mbc.10.3.757

Vinckevicius, A., and Chakravarti, D. (2012). Chromatin immunoprecipitation: advancing analysis of nuclear hormone signaling. J. Mol. Endocrinol. 49, R113R123. doi: 10.1530/JME-12-0016

Waga, S., and Stillman, B. (1998). The DNA replication fork in eukaryotic cells. Annu. Rev. Biochem. 67, 721-751. doi: 10.1146/annurev.biochem.67.1.721

Wahle, E., Lasken, R., and Kornberg, A. (1989). The dnaB-dnaC replication protein complex of Escherichia coli. I. Formation and properties. J. Biol. Chem. 264, 2463-2468.

Wang, J. (2005). Nanomaterial-based amplified transduction of biomolecular interactions. Small 1, 1036-1043. doi: 10.1002/smll.200500214

Wang, M. S., and Reed, S. M. (2012). Direct visualization of electrophoretic mobility shift assays using nanoparticle-aptamer conjugates. Electrophoresis 33, 348-351. doi: 10.1002/elps.201100308

Wang, Y., Knoll, W., and Dostalek, J. (2012). Bacterial pathogen surface plasmon resonance biosensor advanced by long range surface plasmons and magnetic nanoparticle assays. Anal. Chem. 84, 8345-8350. doi: 10.1021/ac301904x

Ward, W. H., and Holdgate, G. A. (2001). 7 isothermal titration calorimetry in drug discovery. Prog. Med. Chem. 38, 309-376. doi: 10.1016/S0079-6468(08)70097-3

Wei, T., and Bernander, R. (1996). Interaction of the IciA protein with AT-rich regions in plasmid replication origins. Nucleic Acids Res. 24, 1865-1872. doi: $10.1093 /$ nar/24.10.1865

Weigel, C., Schmidt, A., Seitz, H., Tüngler, D., Welzeck, M., and Messer, W. (1999). The N-terminus promotes oligomerization of the Escherichia coli initiator protein DnaA. Mol. Microbiol. 34:53-66. doi: 10.1046/j.1365-2958.1999.01568.x

Wilson, S., and Howell, S. (2002). High-throughput screening in the diagnostics industry. Biochem. Soc. Trans. 30, 794-796. doi: 10.1042/bst0300794

Wolański, M., Donczew, R., Zawilak-Pawlik, A., and Zakrzewska-Czerwińska, J. (2014). oriC-encoded instructions for the initiation of bacterial chromosome replication. Front. Microbiol. 5:735. doi: 10.3389/fmicb.2014.00735
Woo, A. J., Dods, J. S., Susanto, E., Ulgiati, D., and Abraham, L. J. (2002). A proteomics approach for the identification of DNA binding activities observed in the electrophoretic mobility shift assay. Mol. Cell. Proteomics 1, 472-478. doi: 10.1074/mcp.T200003-MCP200

Wu, S., Wang, J., Zhao, W., Pounds, S., and Cheng, C. (2010). ChIP-PaM: an algorithm to identify protein-DNA interaction using ChIP-Seq data. Theor. Biol. Med. Model. 7, 18. doi: 10.1186/1742-4682-7-18

Wu, Z., Liu, J., Yang, H., Liu, H., and Xiang, H. (2013). Multiple replication origins with diverse control mechanisms in Haloarcula hispanica. Nucleic Acids Res. 42, gkt1214. doi: 10.1093/nar/gkt1214

Wyrick, J., Young, R. A., Ren, B., Francois, R., and Simon, I. (2009). Genome wide location and function of DNA binding proteins. Science 290, 2306-2309. doi: 10.1126/science.290.5500.2306

Zawilak, A., Durrant, M. C., Jakimowicz, P., Backert, S., and ZakrzewskaCzerwińska, J. (2003). DNA binding specificity of the replication initiator protein, DnaA from Helicobacter pylori. J. Mol. Biol. 334, 933-947. doi: 10.1016/j.jmb.2003.10.018

Zhang, L., Zhang, L., Liu, Y., Yang, S., Gao, C., Gong, H., et al. (2009). Archaeal eukaryote-like Orc1/Cdc6 initiators physically interact with DNA polymerase B1 and regulate its functions. Proc. Natl. Acad. Sci. U.S.A. 106, 7792-7797. doi: 10.1073/pnas.0813056106

Zhang, R., and Zhang, C.-T. (2003). Multiple replication origins of the archaeon Halobacterium species NRC-1. Biochem. Biophys. Res. Commun. 302, 728-734. doi: 10.1016/S0006-291X(03)00252-3

Zhang, R., and Zhang, C.-T. (2005). Identification of replication origins in archaeal genomes based on the Z-curve method. Archaea 1, 335-346. doi: $10.1155 / 2005 / 509646$

Zhang, Y., Akilesh, S., and Wilcox, D. E. (2000). Isothermal titration calorimetry measurements of Ni (II) and Cu (II) binding to His, GlyGlyHis, HisGlyHis, and bovine serum albumin: a critical evaluation. Inorg. Chem. 39, 3057-3064. doi: 10.1021/ic000036s

Zhou, Y., Larson, J. D., Bottoms, C. A., Arturo, E. C., Henzl, M. T., Jenkins, J. L., et al. (2008). Structural basis of the transcriptional regulation of the proline utilization regulon by multifunctional PutA. J. Mol. Biol. 381, 174-188. doi: 10.1016/j.jmb.2008.05.084

Zianni, M., Tessanne, K., Merighi, M., Laguna, R., and Tabita, F. (2006). Identification of the DNA bases of a DNase I footprint by the use of dye primer sequencing on an automated capillary DNA analysis instrument. J. Biomol. Tech. 17, 103-113.

Zijlstra, P., Paulo, P. M., and Orrit, M. (2012). Optical detection of single nonabsorbing molecules using the surface plasmon resonance of a gold nanorod. Nat. Nanotechnol. 7, 379-382. doi: 10.1038/nnano.2012.51

Conflict of Interest Statement: The authors declare that the research was conducted in the absence of any commercial or financial relationships that could be construed as a potential conflict of interest.

Copyright (c) 2015 Song, Zhang and Huang. This is an open-access article distributed under the terms of the Creative Commons Attribution License (CC BY). The use, distribution or reproduction in other forums is permitted, provided the original author(s) or licensor are credited and that the original publication in this journal is cited, in accordance with accepted academic practice. No use, distribution or reproduction is permitted which does not comply with these terms. 